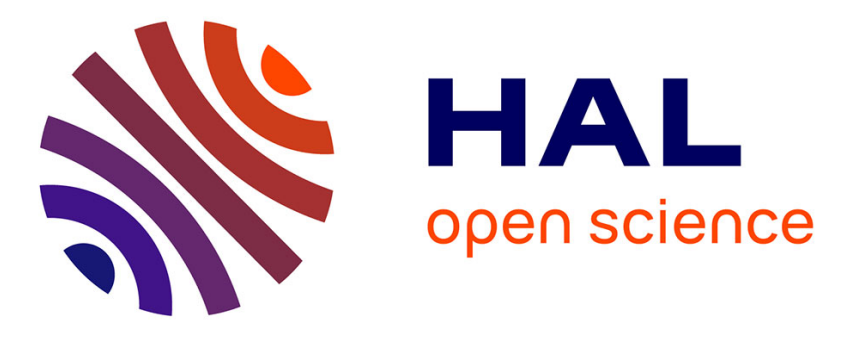

\title{
A GIS-based Urban and Peri-urban Landscape Representation Toolbox for Hydrological Distributed Modeling
}

P. Sanzana, J. Gironas, Isabelle Braud, F. Branger, F. Rodriguez, X. Vargas, N. Hitschfeld, J.F. Munoz, S. Vicuna, A. Mejia, et al.

\section{To cite this version:}

P. Sanzana, J. Gironas, Isabelle Braud, F. Branger, F. Rodriguez, et al.. A GIS-based Urban and Peri-urban Landscape Representation Toolbox for Hydrological Distributed Modeling. Environmental Modelling and Software, 2017, 91, pp.168-187. 10.1016/j.envsoft.2017.01.022 . hal-01826273

\section{HAL Id: hal-01826273 https://hal.science/hal-01826273}

Submitted on 29 Jun 2018

HAL is a multi-disciplinary open access archive for the deposit and dissemination of scientific research documents, whether they are published or not. The documents may come from teaching and research institutions in France or abroad, or from public or private research centers.
L'archive ouverte pluridisciplinaire HAL, est destinée au dépôt et à la diffusion de documents scientifiques de niveau recherche, publiés ou non, émanant des établissements d'enseignement et de recherche français ou étrangers, des laboratoires publics ou privés. 
1 A GIS-based Urban and Peri-urban Landscape Representation Toolbox for 2 Hydrological Distributed Modeling

3 Sanzana, $\mathrm{P}^{\left(1,2,5,{ }^{*}\right)}$, Gironás, J. ${ }^{(1,2,3,4)}$, Braud, I. ${ }^{(5)}$, Branger, F. ${ }^{(5)}$, Rodriguez, F. ${ }^{(6)}$, Vargas, X. ${ }^{(7)}$,

4 Hitschfeld, N. ${ }^{(8)}$, Muñoz J.F. ${ }^{(1)}$, Vicuña, S. ${ }^{(1,4)}$, Mejía, A $^{(9)}$, Jankowfsky S. ${ }^{(10)}$

6 (1) Departamento de Ingeniería Hidráulica y Ambiental, Pontificia Universidad Católica de

7 Chile, Avenida Vicuña Mackenna 4860, Santiago, Chile.

8 (2) Centro de Desarrollo Urbano Sustentable CONICYT/FONDAP/15110020, Avenida 9 Vicuña Mackenna 4860, Santiago, Chile.

10 (3) Centro de Investigación para la Gestión Integrada de Desastres Naturales 11 CONICYT/FONDAP/15110017, Avenida Vicuña Mackenna 4860, Santiago, Chile.

12 (4) Centro Interdisciplinario de Cambio Global, Avenida Vicuña Mackenna 4860, Santiago, 13 Chile.

14 (5) IRSTEA, HHLY, Hydrology-Hydraulic Department, Centre de Lyon-Villeurbanne, 5 rue 15 de la Doua, BP32108, 69126 Villeurbanne, France.

16 (6) LUNAM Université, Institut Français des Sciences et Technologies des Transports de 17 l'Aménagement et des Réseaux (IFSTTAR), Département Géotechnique Eau et Risques et 18 Institut de Recherche en Sciences et Techniques de la Ville (IRSTV), F-44341 Bouguenais, 19 France.

20 (7) Departamento de Ingeniería Civil, Facultad de Ciencias Físicas y Matemáticas, 21 Universidad de Chile, Blanco Encalada 2002, Santiago, Chile.

22 (8) Computer Science Department, Facultad de Ciencias Físicas y Matemáticas, 23 Universidad de Chile. Av. Blanco Encalada 2120, Santiago, Chile.

24 (9) Department of Civil and Environmental Engineering, The Pennsylvania State 25 University, University Park, State College, PA 16802, USA

26 (10) Risk Management Solutions, Inc., Peninsular House, 30 Monument Street, London 27 EC3R 8NB UK 


\section{ABSTRACT}

33 Flowpaths are significantly affected by land use change and engineered elements across

34 urban catchments. Conventional GIS-based tools for extracting drainage networks were not

35 developed for urban terrains. This work presents Geo-PUMMA, a GIS toolbox to generate

36 vectorial meshes for terrain representation in distributed hydrological modeling, and to 37 extract drainage patterns in urban and peri-urban catchments. Geo-PUMMA generates well-

38 shaped Hydrological Response Units (HRUs) and Urban Hydrological Elements (UHEs).

39 The toolbox was used in peri-urban catchments of Chile and France to generate three model

40 meshes with different levels of treatment, and extract and compare their corresponding

41 drainage networks. A recommended mesh is identified, which replicates the main

42 morphological and hydrological features of the reference drainage network, and is able to

43 preserve features at small to medium spatial scales $(\sim 80-150 \mathrm{~m})$. Overall Geo-PUMMA

44 can be used to represent the terrain in distributed hydrological modeling applied to urban 45 and peri-urban scales.

46

47

48 Keywords: Peri-urban catchments; Hydrological Response Units; Urban Hydrological

49 Elements; Drainage extraction; Computer-assisted mesh generation 
51

52 Availability: https://forge.irstea.fr/projects/geopumma.

53 Additional technical documentation: A user manual with an example database available

54 from the same web address.

55 Year First Available: 2016

56 Hardware Required: Desktop/Laptop with 2 GHz CPU, 4 GB RAM or more

57 Operating System Required: Ubuntu 14 (64b) or newer

58 Software required: Geo-MHYDAS,-GRASS GIS 6.4, QGIS 2.12. These software and other

59 plugins and libraries are packaged in a Virtual Box Machine available from the same web

60 address

61 Cost: Free

62 Program Language: Python

63 License: GNU General Public License

64

65 Geo-PUMMA was developed in GRASS 6.4 in a virtual machine with Ubuntu 14 (64b).

66 Although programming skills are not needed, Geo-PUMMA requires some knowledge on

67 spatial analysis and hydrological modeling. It is necessary to be familiar with the use of 68 commands and to have basic knowledge of urban hydrology that allow making decisions 69 when representing urban features. 


\section{INTRODUCTION}

Urban development significantly changes the hydro-geomorphology of natural river catchments and their drainage networks (Booth and Henshaw, 2001; Booth and Fischenich, 2015; Vietz et al., 2015). Some of the most impacted areas are located in so-called periurban catchments, where urban development is often ongoing, and natural, rural and urban areas coexist (Santo Domingo et al., 2010). Peri-urban catchments are particularly vulnerable to environmental change with urban development drastically modifying the landscape (Lee and Heaney, 2003; Shuster et al, 2005) and changing the connectivity of surface and sub-surface flowpaths (Braud et al., 2013). Thus, the accurate characterization and representation for modelling purpose of these catchments becomes essential.

The representation of surface flowpaths at small scales is critical in hydrological modeling of urban and peri-urban areas. Such representation must consider not only channelized elements, but also the connectivity of impervious and pervious surfaces (Sanzana et al., 2013; Rossel et al., 2014). In small catchments, surface routing is sensitive to the presence of relatively small channels, which can be highly responsive to intense and short rainfall events (Singh, 1995). Moreover, Rossel et al. (2014) showed that the connectivity among pervious and impervious areas affects the magnitude and relative contribution of the different mechanisms that ultimately influence the overall catchment response. Finally, Jankowfsky (2011) showed how the use of inappropriate polygon meshes to represent the terrain affects the correct connectivity of hydrological elements.

Several GIS tools have been developed to represent and visualize landscapes and extract information for hydrological modeling. Classical methodologies of drainage extraction and catchment delineation use Digital Elevation Models (DEM) and raster-based flow direction algorithms, such as the D8 (O'Callaghan \& Mark, 1984) or Multiple Flow Directions (MFD) algorithm (Holmgren, 1994; Toma et al., 2001; Seibert and McGlynn, 2007). Furthermore, mathematical filters can be used with high-resolution DEM to detect curvatures and slope directions, and define valleys and likely channelized locations in the catchment (Lashermes et al., 2007; Passalacqua et al., 2010; Sangireddy et al., 2016). These algorithms only extract well-defined streams and work fine in natural and non-flat areas at regional or medium scales $\left(\sim 100-1000 \mathrm{~km}^{2}\right)$, but tend to fail at smaller scales associated with urban and peri-urban areas and catchments $\left(<0.1-10 \mathrm{~km}^{2}\right)$, where surface and 
101 subsurface infrastructures can modify dramatically flow paths and catchments' boundaries 102 (Gironás et al., 2010; Jankowfsky et al., 2013; Rodriguez et al., 2013). These tools 103 represent the terrain using cells of the same shape and size (e.g. square grid cells), but other non-uniform meshes composed of triangles or polygons can also be used to avoid the 105 oversimplification of interfaces between hydrological elements, while reducing as much as 106 possible the number of elements in the final model mesh.

Good examples of GIS tools on raster-based are GRASS-HRU (Schwartze, 2008), WINHRU (Viviroli et al., 2009) and GRIDMATH (Viviroli et al., 2009), and vector-based are AVSWAT (Di Luzio et al., 2004), and PIHMgis (Bhatt et al., 2014). These tools use Hydrological Response Units (HRUs) as elementary units, but they were developed to

111 represent medium and regional scale areas, so urban and peri-urban elements are normally not well captured. Tanato2 (Bocher and Martin, 2012) is a GIS tool that uses Triangular Irregular Networks (TINs) to represent complex urban and peri-urban terrains and their special features and elements, as well as the interface between hydrological elements.

115 Nonetheless, the final mesh is composed only of triangles, and thus has notably more elements than irregular meshes. Geo-MHYDAS (Lagacherie et al., 2010), a tool that uses meshes conformed by irregular shape polygons developed for agricultural areas, is not 118 suitable for representing urban elements either, as it cannot deal with topological problems typically found in urban terrain meshes (e.g., non-convex polygons, complex boundary 120 interfaces and large polygons).

121 Despite the afore mentioned advances in terrain representation for hydrological 122 modelling, the extraction of flow paths and the hydrological analysis of urban and peri123 urban environments handling man-made hydraulic features (e.g., ditches, channels and 124 pipes) is still an open scientific question. To the best of our knowledge, no specific tool is 125 available yet to generate good quality polygonal meshes for urban and peri-urban 126 catchment, i.e. a mesh composed of the least possible number of properly interconnected 127 well-shaped elements. A well-shaped element is a not-so-thin-and-slim pseudo-convex 128 polygon hydrologically homogenous, which allows the identification of the hydrologic 129 connectivity defined by the terrain, and ensure the efficient application of hydrological 130 models. 
The objective of the paper is to present and illustrate the use of Geo-PUMMA, a GIS tool to generate polygonal meshes for urban and peri-urban terrain representation, from which a spatial characterization of the hydrological attributes, as well as an accurate connectivity for distributed hydrological modeling, are obtained. After describing its structure and main components, we illustrate an application of Geo-PUMMA for hydrogeomorphological characterization of peri-urban catchments, with a particular focus on their drainage network and its representation with different mesh alternatives whose quality are assessed using geometrical and hydrological descriptors. Generally, the expression "drainage network" refers to the network of pipes and streams conveying flow to the outlet. In this paper, this concept refers to the whole connectivity structure among the hydrological elements within the catchment contributing to the channelized system (streams, ditches and sewer). Two catchments located in different landscapes and climatic conditions were chosen: the Estero El Guindo catchment (Santiago, Chile), and the Mercier catchment (Lyon, France).

\section{Geo-PUMMA}

\subsection{General presentation of Geo-PUMMA}

Geo-PUMMA is a semi-automatic toolbox to spatially represent urban and periurban catchments and the explicit hydrological connectivity among their components, for the subsequent implementation of semi-distributed and distributed hydrological modeling. It uses a vectorial approach to produce irregular shape elements that are representative of the principal physiographic units of small catchments $\left(0.1-10 \mathrm{~km}^{2}\right)$. Geo-PUMMA can explicitly consider not only natural features, but also artificial infrastructures implemented in urban and peri-urban environments (e.g., hydraulic infrastructure, detention and retention devices, pipes and streets). Urban features are represented using Urban Hydrological Elements (UHEs) (Rodríguez et al., 2008), while natural/rural areas are depicted using Hydrological Response Units (HRUs) (Flügel, 1995). These units are represented using varying-size, irregular shape polygons.

Geo-PUMMA builds upon the tools initially developed to process geospatial information and represent peri-urban terrain in the hydrological model PUMMA (Jankowfsky et al., 2014). This development is reported elsewhere in the literature (i.e., 
162

163

164

165

166

167

168

169

170

171

172

173

174

175

176

177

178

179

180

181

182

183

184

185

186

187

188

189

190

191

192

Paillé, 2010; Brossard, 2011; Jankowfsky, 2011; Sanzana et al., 2013). These tools were developed using different computer languages and software (i.e. SQL, R scripts and GRASS functions). Geo-PUMMA not only consolidates these tools in order to simplify their use and the data processing, but also includes new functionalities. Geo-PUMMA is implemented on the GRASS platform (GRASS Development Team, 2015) and QGIS (Quantum GIS Development Team, 2015), and the corresponding codes are written in Python programming language (python.org) due to the advantages of topological management and available commands to process vector grids.

Geo-PUMMA considers four main steps covering the whole analysis process going from data gathering and digitalization up to the derivation of the hydrological connectivity. The first step (Step A) corresponds to data collection, digitalization and quality improvement of all the geospatial maps relevant for the modeling of urban and peri-urban hydrologic processes. The second step (Step B.1) corresponds to the description of the urban area, in which all the UHEs are delineated and characterized using attributes such as average height, area, percentage of imperviousness, green area, and distance from the centroid to the closest sewer or street. In the third step (Step B.2) the initial HRUs segmentation is improved using triangulation and dissolution processes based on the socalled geometric indexes. In this step HRUs can also be segmented to lump the topographic properties obtained from the DEM (Sanzana et al., 2013), including the slope, aspect, etc. In the fourth step (Step B.3), the drainage network is extracted using a recursive algorithm for identifying surface and sub-surface flow directions, and considering hydrological connections among the different units. The obtained drainage network is composed of the channelized infrastructure, natural streams and the entire connectivity among the HRUs and UHEs draining to the channelized system (streams, ditches and pipes). A final step not performed by Geo-PUMMA is needed to transform the geospatial features into database tables to be processed by the hydrological model. For example, in the case of the PUMMA model (Jankowfsky, 2011, Fuamba et al., 2015), this step uses SQL scripts developed by Jankowfsky (2011). The resulting features can also be used in other models such as SWMM (Gironás et al., 2010), SWAT (Neitsch et al., 2005), URBS (Rodriguez et al., 2008) or MHYDAS (Moussa et al., 2002). Table 1 summarizes the different scripts implemented in Geo-PUMMA, which can be of optional or compulsory use. The Geo-PUMMA Tutorial 
193 (Geo-PUMMA Team, 2017) provides details and an example on how to use these scripts, 194 that will give the user an idea of the computing times involved.

Although Geo-PUMMA is a self-contained tool including the scripts developed to 196 implement this 4 step methodology, certain GRASS and Geo-MHYDAS scripts 197 (Lagacherie et al., 2010) are needed for some specific steps, and should be installed together with Geo-PUMMA (Appendix 1 presents the main functions used in addition to 199 Geo-PUMMA). From now on in the text, m.script and vfunction correspond to external 200 Geo-MHYDAS scripts and GRASS functions respectively. Readers are referred to the 201 GRASS (GRASS Development Team, 2015) and Geo-MHYDAS (Lagacherie et al., 2010; 202 Openfluid Project, 2016) documentation to learn about the use and implementation of these 203 scripts. Nonetheless, a Virtual Box Machine with all the tools and external scripts is 204 available from the Geo-PUMMA downloading site. More details and examples are 205 available in the Geo-PUMMA Tutorial. What follows is a description of the four steps 206 considered in Geo-PUMMA.

207

208 Table 1. Tasks in each step of Geo-PUMMA and the corresponding scripts

\begin{tabular}{|c|c|c|}
\hline & Script/Plugin & Task (optional/compulsory) \\
\hline \multirow[t]{2}{*}{ Step A } & p. clean_topology.py & Cleaning topological polygons (compulsory) \\
\hline & p. clean_polyline.py & Snapping, breaking and joining polylines (optional) \\
\hline \multirow[t]{6}{*}{$\begin{array}{l}\text { Step } \\
\text { B.1 }\end{array}$} & p.sidewalk_street.py & $\begin{array}{l}\text { Segmenting part of sidewalk and street in front of each urban } \\
\text { lot (compulsory) }\end{array}$ \\
\hline & p.uhe.py & Creating the UHE shapefile (compulsory) \\
\hline & p.a.average_altitude.py & $\begin{array}{l}\text { Getting the mean altitude and statistical parameters of each } \\
\text { UHE (compulsory) }\end{array}$ \\
\hline & pc.wood_surface.py & Getting the green area percentage of each UHE (optional) \\
\hline & p.length.py & $\begin{array}{l}\text { Getting the distance from the centroid to the street centerline } \\
\text { (compulsory) }\end{array}$ \\
\hline & p.built.py & Getting the building percentage of each UHE (optional) \\
\hline \multirow{2}{*}{$\begin{array}{l}\text { Step } \\
\text { B. } 2\end{array}$} & p.polygons_holes.py & Segmenting the HRU with island inside (optional) \\
\hline & p.shape factors.py & Calculating shape factors (convexity index, solidity index, \\
\hline
\end{tabular}




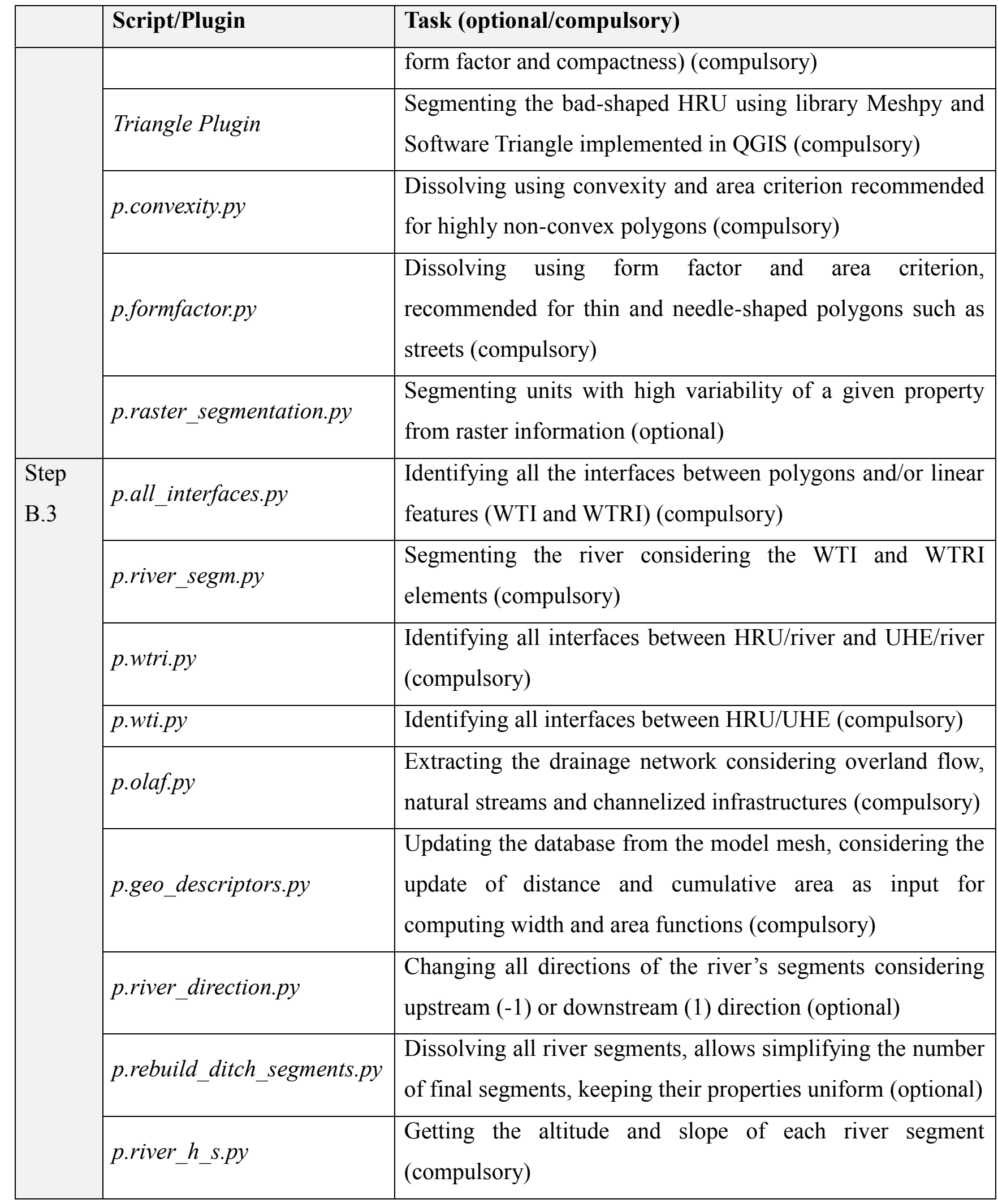


The aim of Step A is to collect and pre-process all the relevant maps containing 212 spatial information, including urban cadastral maps, land use maps, vegetation, soil type 213 and geology layers, as well as natural and urban channelized networks (Fig.1). The pre214 processing allows generating maps with clean topology to be used in the next steps. In 215 addition to digitalized private and public lots, the cadastral maps should include public built 216 areas (e.g., streets, squares and parks, sport and recreation areas, trails and bike paths). 217 Certain infrastructures can be digitalized from high-resolution aerial photos, LiDAR (Light 218 Detection and Ranging) images or similar, with resolutions finer than $0.5 \mathrm{~m}$. Much of this information is available on-line, but some is found in urban data banks prepared and maintained by municipalities and public or private institutions. Green and natural areas as well as crops can be identified from satellite information and manually digitalized (Banzhaf et al., 2013; Jacqueminet et al., 2013). Finally, minor hydraulic infrastructure such as diversion elements, culverts and drains can be identified from field surveys.

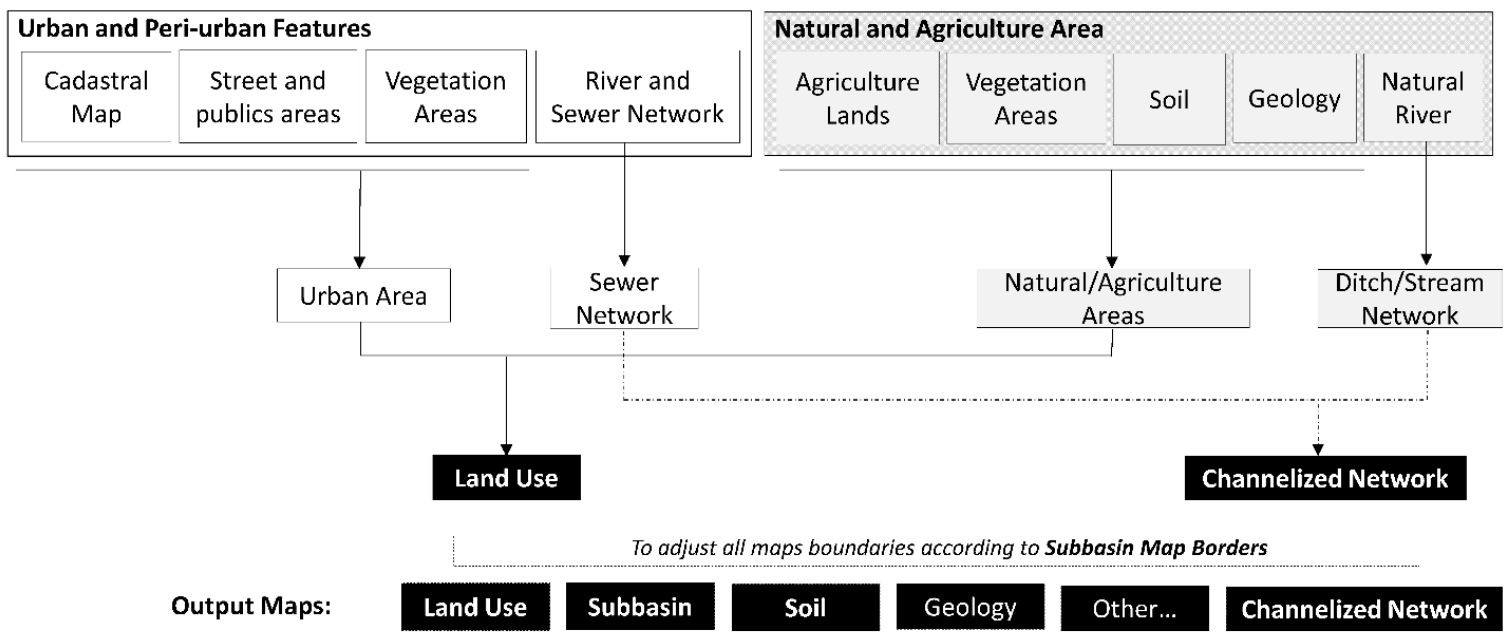
processing of input information

Although most of the algorithms developed for remote sensing images consider a raster format, the resulting maps are vector layers (i.e., polygons, polylines). As expected, the quality of these maps and the subsequent computation of lumped properties such as

231 height, slope and aspect, depend strongly on the resolution of the original DEM.

232 Once the basic polygonal layers have been collected, we recommend correcting 233 linear elements such as rivers to avoid topological mistakes in the intersection step (Fig.2a), 
234

235

236

237

238

239

240

241

242

243

244

245

246

247

248

249

250

251

252

253

254

255

256

257

258

in which all the polygon or polyline layers are overlapped. Thus, the channelized network must be adjusted to one side of the street or to the closest edge elements to avoid the creation of small irrelevant units for hydrological modeling (Fig.2b). Additionally, at this step the edges of the lower resolution maps (e.g., soil type and geology) must be adjusted to those with higher resolution (i.e., cadastral maps). Linear elements can only be adjusted manually in a very time consuming manner given the length of channelized networks. Nevertheless, as such correction is not included in Geo-PUMMA, we recommend using a semi-automatic snapping tool such as the m.snaplp script, which allows snapping automatically the vertex of the polyline to the nearest element (Fig.2c).
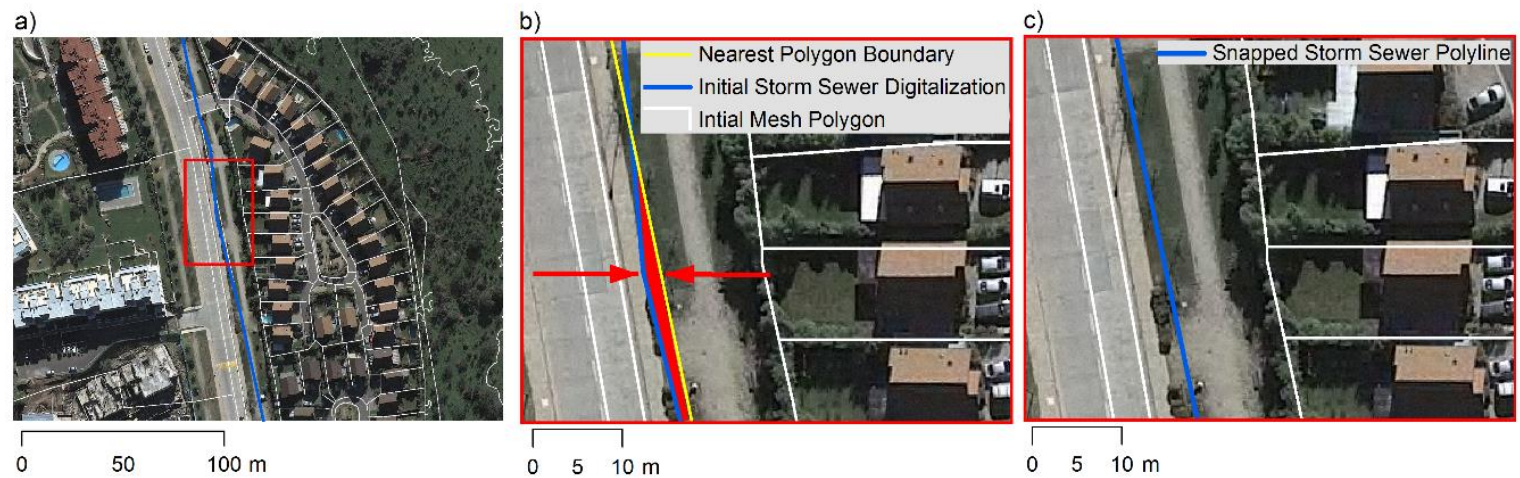

Figure 2. Correction of linear elements to avoid topological mistakes when intersecting different maps. (a) a particular urban location containing polygons from the initial mesh (white polygons) and a digitalized storm sewer (blue polyline). (b) a sliver area (red polygon) is created when intersecting the storm sewer and the initial mesh, which can be removed by snapping the polyline to the nearest polygon boundary (yellow line). (c) After the correction, the storm sewer overlaps the polygon boundary.

The next step is the delineation of the catchment and sub-catchment boundaries using all the available related maps (e.g., land use, sub-catchments, soil and geology). If a single stream network exists, the delineation based on the DEM can be a first approximation, and drainage infrastructures (e.g., sewers and ditches) can be used later to refine the boundaries. In fact, stormwater or combined sewer networks can hinder the delineation and definition of urban sub-catchments, and field surveys become crucial to achieve this task (Jankowfsky et al. 2013). Finally, the limits of each of the input maps must coincide exactly to generate the initial overlapped map. Each shapefile must be 
259 imported into a GRASS database using p.clean_topology.py and p.clean_polyline.py to

260 avoid topological problems in polygonal and polylines features respectively.

262 2.3. Step B.1: Delineation and characterization of UHEs

263 To create the UHEs, urban lots, land plots and streets are first extracted from the 264 land-use layer (Fig. 3, step B.1) in which all the built elements are digitalized. A relevant 265 input for the definition of the UHEs is the polyline representing the axis of every street, 266 from which the distance to each UHE is computed. Because no specific script is available 267 in Geo-PUMMA, these street axes must be obtained from public or private database, or 268 digitalized from the urban street layer either manually or using computer-assisted tools 269 proposed elsewhere (Hu et al., 2004; Haunert and Sester, 2008; Leninisha and Vani, 2015). 270 Only scripts from Geo-PUMMA are needed to create the UHEs, and no extra tool is 271 required. The p.sidewalk_street.py script generates the sidewalk and street layer, and 272 identifies the sidewalk and half of the street in front of each lot. This layer and the cadastral 273 map are used by the p.uhe.py script to create the UHEs (see an example of final UHEs in 274 Fig. 4). Different scripts are then used to assign different attributes to each UHE, including: 275 average height (p.average_altitude.py), distance from the centroid to the center of the street 276 (p.length.py), built area in each lot (p.built.py), and the fraction of trees by lot 277 (p.wood_surfaces.py) in case a detailed digitalization of each lot is available. Alternatively, 278 Banzhaf et al. (2013) propose digitalizing the green areas of a random representative set of 279 lots to build a simple statistical relationship between the lot area and the percentage of 280 green area. 

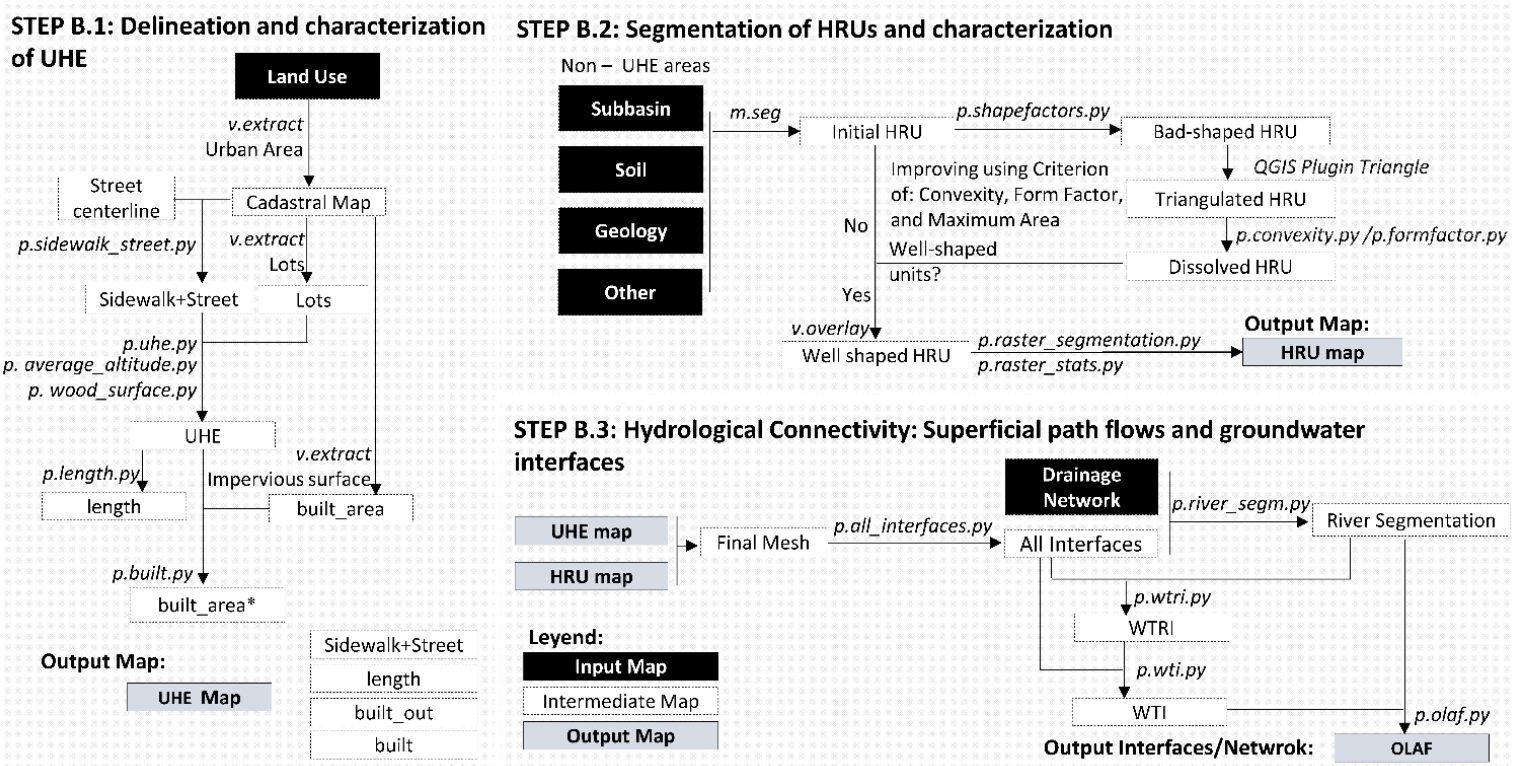

STEP B.3: Hydrological Connectivity: Superficial path flows and groundwater interfaces

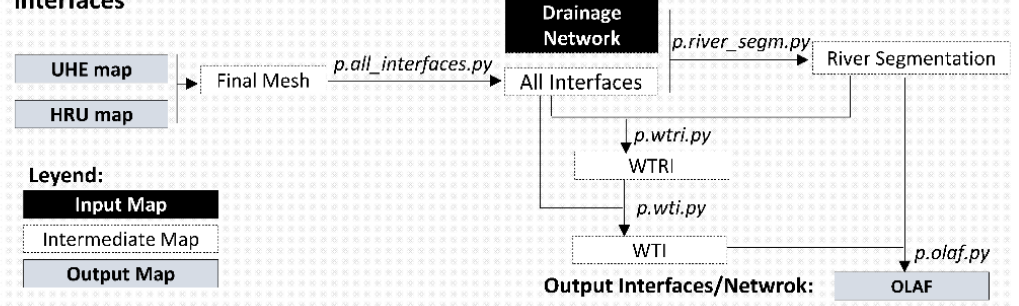

Figure 3. Flowcharts showing Step B.1 (UHE characterization), Step B.2 (HRU characterization) and Step B.3 (Hydrological connectivity description)
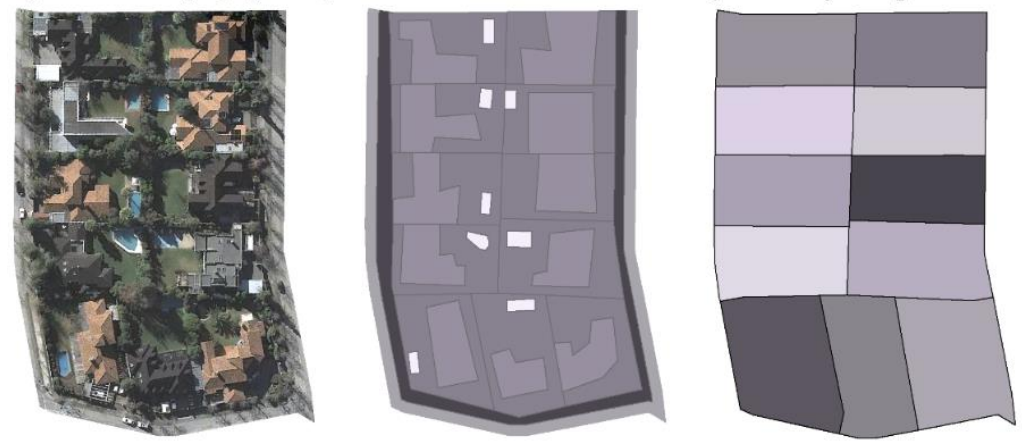

Figure 4. Example of UHEs generation in Geo-PUMMA. (a) Aerial Photography; (b)

\subsection{Step B.2: Segmentation of HRUs}

\subsubsection{Initial HRUs}

The first step to obtain the initial HRUs is to intersect the main vector layers selected in Step A, excluding the UHEs. Usually, the tools to intersect layers in GIS platforms only operate with polygon layers (e.g. land use, sub-catchments, soil, and geology), but cannot intersect polygons with polylines (e.g. rivers and channels). Such capability is very relevant for peri-urban catchments. Thus, we propose using the script m.seg, although polygons features could also be intersected first, and subsequently the 
polylines features could be manually used to cut the polygons they intersect. Subsequently, the scripts m.dispolygseg and m.sliverpolygseg should be used to clean the resulting layers; m.dispolygseg dissolves the smallest areas to a certain threshold value, whereas m.sliverpolygseg dissolves areas with an elongated thin shape. One could also consider using the GRASS function v.clean, although it dissolves all the longest boundaries of the units below an area threshold.

The direct intersection of maps allows the identification of areas with homogeneous properties, although the initial mesh is composed of elements of very irregular geometry. As the distances between the centroid of the polygons are commonly used to represent the mean flow distance among units, bad-shaped elements must be corrected to avoid affecting hydrologic simulation. We define a good quality polygonal mesh for urban and peri-urban catchments as a mesh composed of the least possible number of properly interconnected well-shaped elements, with homogenous hydrological properties, that are representative of the terrain and ensure the efficient application of hydrological models. Hence, the following criteria must be satisfied (Sanzana et al. 2013): (1) the centroid must be inside each element, (2) the boundaries must be smooth, (3) the area of each element must be in a certain range, and (4) narrow and elongated elements must be avoided. In the following subsections, we present the process to correct the bad-shaped elements.

\subsubsection{Identification of bad-shaped HRUs}

Bad-shaped elements can be identified after using the script p.shapefactors.py, which computes for each HRU the geometric indexes Convexity Index $\left(C I=A_{C} / A\right)$ and Form Factor $\left(F F=16 A / P^{2}\right)$, where $A$ is the area of the polygon, $A_{c}$ is the convex area and $P$ is the perimeter of the polygon. $C I$ allows identifying HRUs with irregular shape in which the centroid is generally outside, whereas $F F$ allows identifying thin and long units. $C I=1$ for regular shape polygons such as circles, squares and rectangles, whereas $C I<1$ for any non-convex units. On the other hand, $F F=1$ for square polygons, and $F F<1$ for thin and long units. Finally, elements with a large area must be partitioned into new smaller areas.

A good quality mesh will be composed of well-shaped elements whose areas range between a minimum and maximum value ( $A_{\min }$ and $A_{\max }$ respectively), and for which $C I$ and $F F$ are larger than certain threshold values $C I_{\min }$ and $F F_{m i n}$. First, the small elements 
with no relevant physical significance must be dissolved by means of the m.dispolygseg or $v$.clean scripts. A threshold area of $A_{\min }=10 \mathrm{~m}^{2}$ is recommended for peri-urban landscapes. Subsequently, elements with area larger than $A_{\max }$ must also be identified and segmented. A value $A_{\max }=2$ ha is recommended for peri-urban areas. Second, elements with $F F<F F_{\min }$ (i.e. narrow and thin units) and elements with $C I<C I_{\min }$ are identified.

As a result, three independent bad-shaped subsets associated with the geometric or area criteria are generated. The subset with small polygons $\left(A<A_{\min }\right)$ must be dissolved and is not considered in the segmentation procedure. Because the bad-shaped units will be triangulated to avoid increasing the processing times, the user must verify that the number of vertexes of each subset does not exceed a certain value using the v.info script. We suggest a maximum of 500 vertexes/ha to represent spatial features such as green areas. Nevertheless, the function v.generalize can be used to simplify those elements in GRASS, with its option for reducing the number of vertexes in a boundary using either the DouglasPeucker (Douglas and Peucker, 1973) or Snakes (Kass et al., 1988) algorithm.

\subsubsection{Improvement of bad-shaped HRUs}

To improve bad-shaped units Geo-PUMMA uses a divide and conquer approach, in which the bad-shaped HRUs are segmented into a subset of triangles using the software Triangle (Shewchuck, 1996) prior to grouping new well-shaped units. Two options are considered for triangulation: (1) $R$ scripts developed by Sanzana et al. (2013) to compile Triangle, or (2) the Triangle Plugin available in QGIS, which uses the Meshpy library to perform a triangulation over the shapefiles. Finally, the triangulated subset obtained using the convexity criteria $\left(C I>C I_{\min }\right)$ is dissolved utilizing the p.convexity.py script, whereas the p.formfactor.py script is used for the subset obtained using the form factor criteria $(F F>$ $\left.F F_{\text {min }}\right)$. The divide and conquer algorithm allows the segmentation using not only a convexity criterion already presented in Sanzana et al. (2013), but alternatively a form factor criterion developed especially for Geo-PUMMA, whose pseudo-code is presented in the Appendix 2 and illustrated in Fig. 5. The urban area in Fig.5a includes a street surrounding a square, which corresponds to a bad-shaped element with $F F=0.06$ (Fig.5b.1). The segmentation of this polygon considers adding vertexes every $5 \mathrm{~m}$ or less (Fig.5b.2), the subsequent triangulation (Fig.5b.3) and dissolving to generated 10 pieces 
with $F F>F F_{\text {min }}=0.4$ (Fig.5b.4). Finally the new mesh is composed of well-shaped and small elements (Fig 5c).
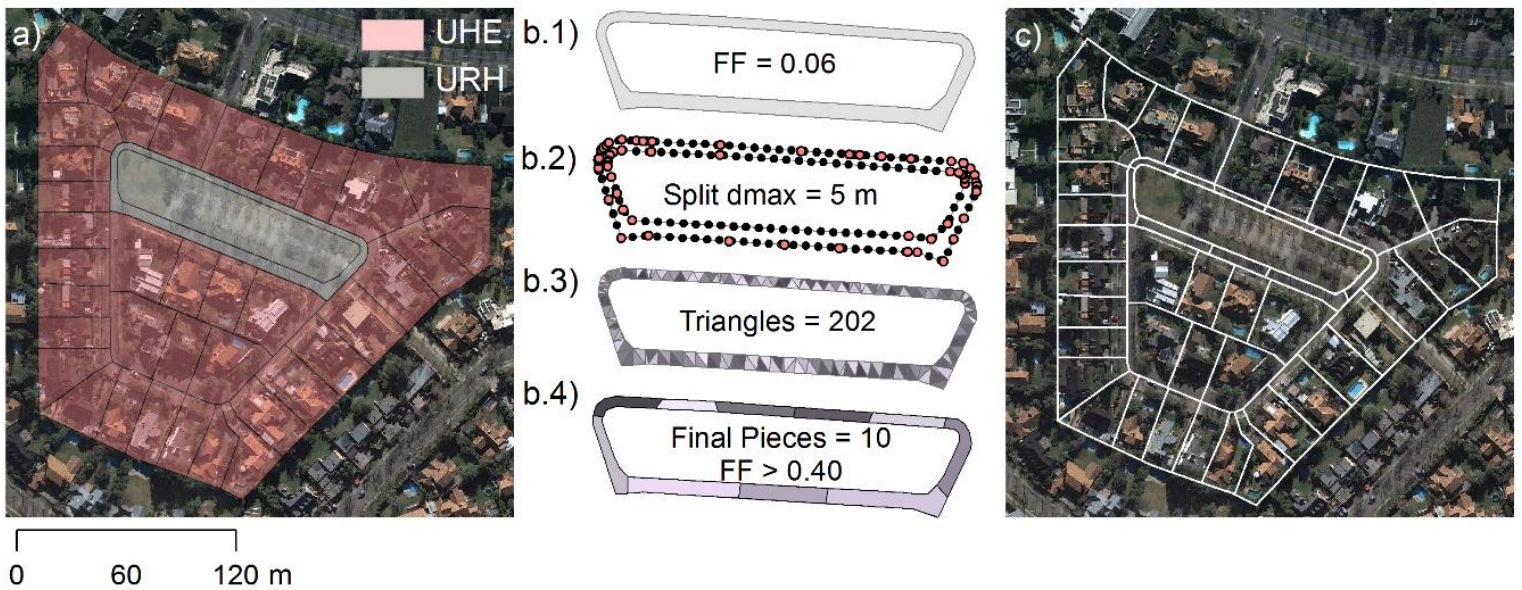

Figure 5. An example of a bad-shaped polygon improvement. (a) a long and

thin street surrounding a square is generated. (b) The street corresponds to a bad$\left.F F_{\min }=0.4\right)$. (c) final improved mesh.

This process produces a good quality mesh made up of well-shaped elements that still may have small area units and/or elongated triangles. A new application of the p.shapefactors.py routine allows identifying units with $A<A_{\max }, C I<C I_{\min }$ and $F F<F F_{\min }$ values. The iterative application of the divide and conquer approach using $C I$ or $F F$ criteria can produce new small bad-shape elements, as these criteria may sometimes not be compatible. Small elements without hydrological meaning are finally dissolved, whereas the others are kept in the final mesh despite not fulfilling the geometric criteria.

Fig. 6 illustrates the use of the script p.convexity.py in the segmentation of a badshaped unit. The unit (Fig. 6a) is divided in triangulated units (Fig. 6b), which are dissolved

3767 illustrates the use of the script p.formfactor.py in the segmentation of a bad-shaped unit 377 with a thin and long shape. The thin element (Fig. 7a) is divided in triangulated units (Fig. $378 \mathrm{7b}$ ) that are dissolved into polygons using threshold values of $F F_{\text {min }}=0.50$ (Fig. $7 \mathrm{c}$ ) and $379 \quad F F_{\min }=0.20$ (Fig. 7d). 
380

381

382

383

384

385

386

387

388

389

390

391

392

393 a)

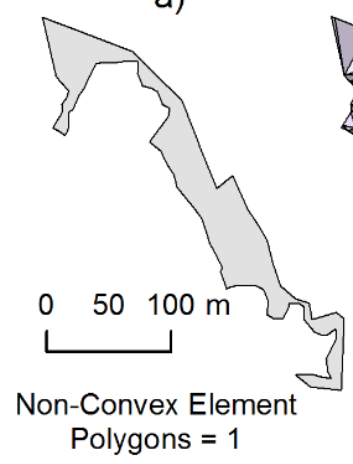

b)

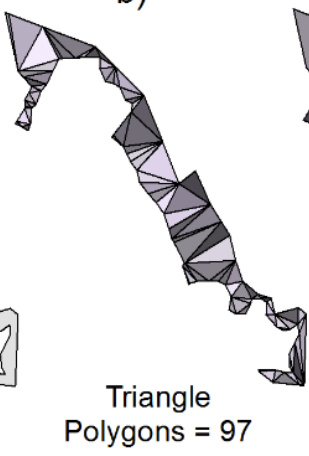

c)

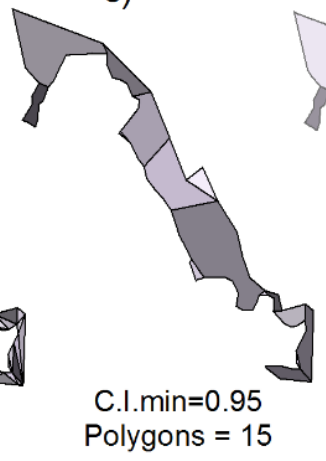

d)

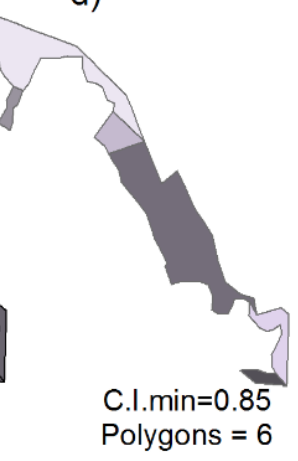

Figure 6. HRU segmentation according to Convexity Criterion. Initial Polygon (a), Triangulated Polygon (b), Dissolved with $C I_{\min }=0.95$ (c) and $C I_{\min }=0.85$ (d)

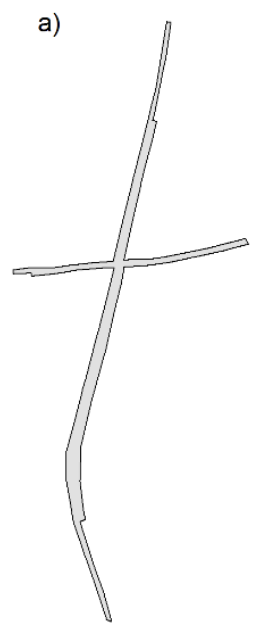

Thin Element Polygons: 1
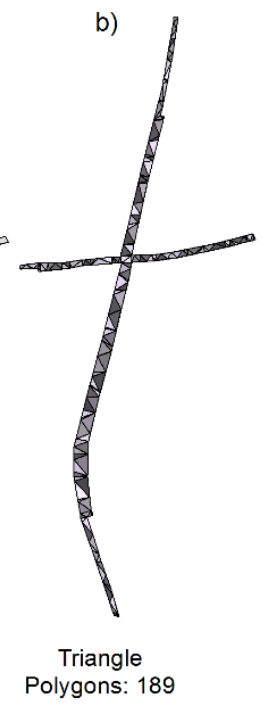

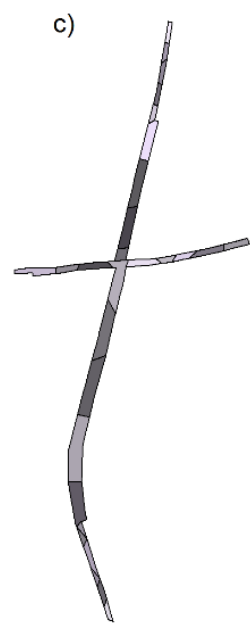

F.F.min $=0.50$ Polygons: 27

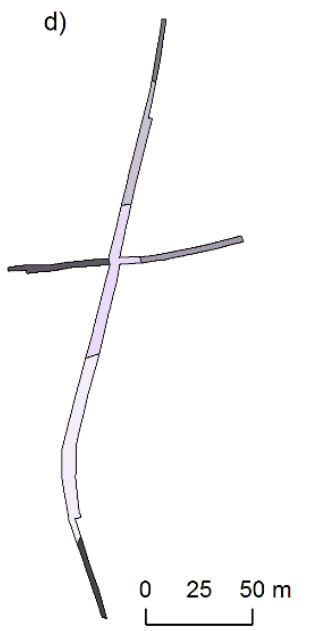

F.F.min $=0.20$ Polygons: 6

Figure 7. HRU segmentation according to Form Factor Criterion. Initial Polygon (a), Triangulated Polygon (b), Dissolved with $F F_{\min }=0.50$ (c) and $F F_{\min }=0.20$ (d)

\subsubsection{Segmentation by raster criterion}

The final segmentation step using the p.raster_segmentation.py routine (Sanzana et al., 2013) is applied to the HRUs with high internal variability of topographic attributes, such as slope or aspect. This script creates new more homogeneous units and facilitates the extraction of a more realistic hydrological connectivity.

2.5. Step B.3: Hydrological connectivity 

extracted from the improved mesh (Fig. 3, Step B.3). Routing algorithms are applied considering the centroid of the units directly connected to the drainage system. The length of the interface between adjacent units is used to estimate the lateral subsurface flow between two units (HRU or UHE) or between one unit and the river. The hydrological interfaces are identified using the p.all_interfaces.py routine. Then, the initial river (Fig. 8a) is segmented based on the boundary of the adjacent units using the p.river_segm.py routine (Fig. 8b). In addition, the p.wti.py and p.wtri.py scripts are used to identify all the interfaces through which flow exchange between the river and neighboring units occurs. These interfaces are defined as WTRI (Water Table River Interfaces) and WTI (Water Table Interfaces) (Fig. 8b).
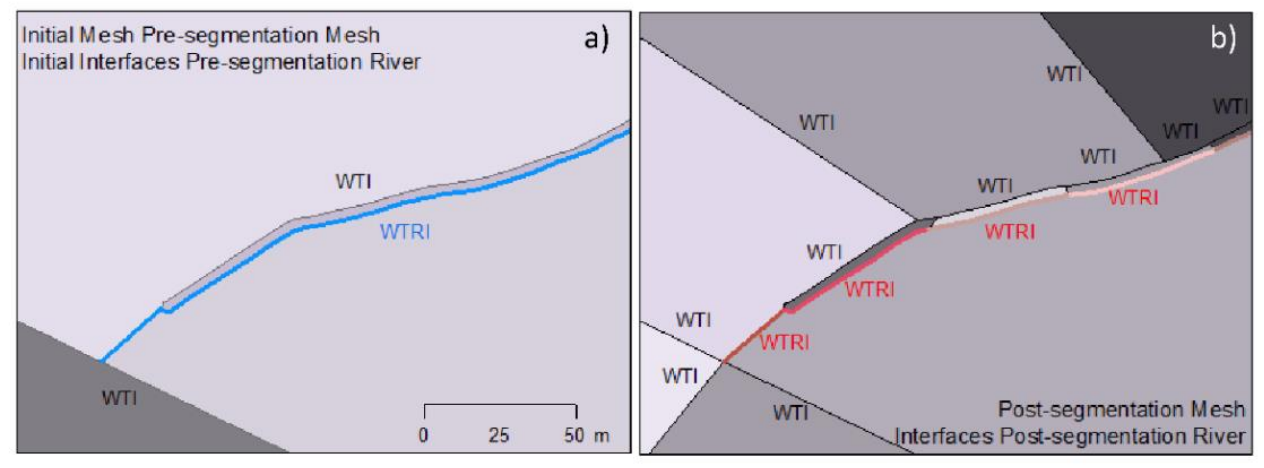

Figure 8. Initial River (a) and Segmented River (b) based on HRU neighbors

The p.olaf.py routing algorithm (Brossard, 2011) connects first all river segments bordering HRUs and all the isolated HRUs with only one neighbor. Then, for the remaining HRUs, it looks for the minimal height until reaching the river or channel section. As a result, a vector layer with the hydrological connectivity of the HRUs and UHEs is obtained. If a loop is generated within the process, the algorithm recursively looks for an alternative route from the unit starting the loop until reaching the drainage system (the pseudo-code of the OLAF algorithm is presented in Appendix 3, its flowchart in Fig. 9 and an example of

417 the search is only carried out inside each sub-catchment, and avoids leaps to neighboring 418 catchments as the topographic boundaries previously imposed are respected. The p.olaf.py 
419 algorithm also delivers the HRUs subset that could not be connected to the general system.

420 In this case, the heights must be verified and the routine run again. A manual checking and 421 connection is eventually needed only when bad-shaped elements or big flat units produced 422 by the previous segmentation still remain.

423 The p.geo_descriptors.py routine can be used to perform a detailed analysis of the 424 spatial distribution of the connected area. This routine stores the area -or any other property 425 whose value is spatially distributed- and distance to the outlet point. This information can 426 then be used to compute the width and area function, two geomorphological functions 427 utilized later to characterize the drainage networks generated by Geo-PUMMA. In a final 428 step, the direction of the drainage system can be defined from downstream or upstream 429 with the p.river_direction.py script. Furthermore, in order to minimize the number of 430 stream reaches and reduce computation time, portions of them with similar characteristics 431 (particularly height) can be dissolved with p.rebuild_ditch_segments.py, while the height 432 and slope are reassigned with the $p . r i v e r \_h \_$py script.

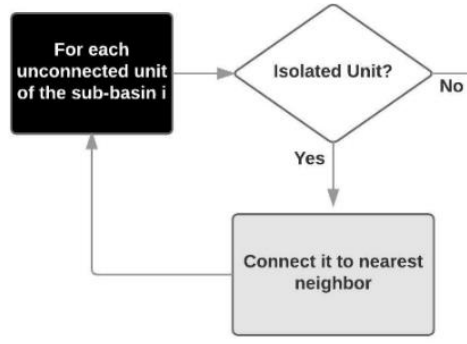


436

437

438

439

440

441

442

443

444

445

446

447

448

449

450

451

452

453

454

455

456

457

458

459 a)

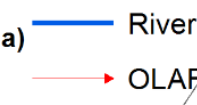

River

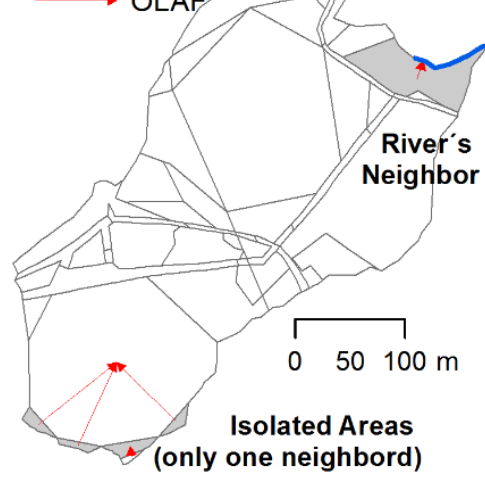

b)

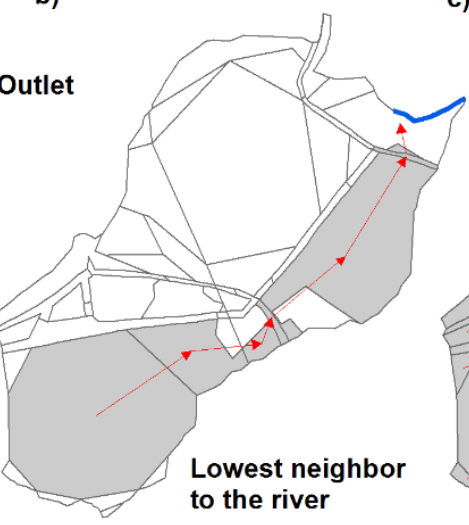

c)

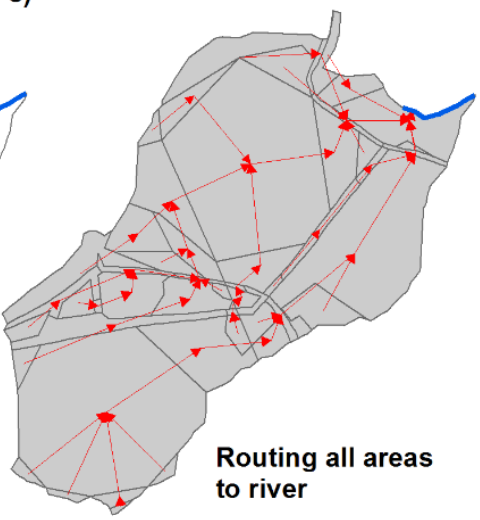

Figure 10. An example of the OLAF algorithm. a) Connection of neighboring river units to the river and isolated polygons with neighbor polygon, b) routing upper units into downstream unit and c) routing until connecting all units

\section{APPLICATION OF Geo-PUMMA TO TWO CASE STUDIES}

As an application example, Geo-PUMMA was implemented in two peri-urban catchments located in different geographical regions, to create and geomorphologically and hydrologically compare 3 particular meshes generated by the model and the corresponding drainage networks. This application illustrates the performance and flexibility of GeoPUMMA when used in diverse landscapes with different data availability and format, and allows recommending strategies and parameter values to obtain good-quality meshes. In addition, the final segmentation obtained with Geo-PUMMA is qualitatively compared against the application of a traditional raster-based approach, in order to show the advantage of the Geo-PUMMA vectorial approach. As a reference, the application of GeoPUMMA to the study catchments here described implied computing times of $\sim 60 \mathrm{~h}$.

\subsection{Study areas and available information}

\subsubsection{Estero el Guindo catchment, Santiago (Chile)}

The Estero El Guindo catchment (Fig. 11a) is located in the Andean foothill, in a rapidly expanding peri-urban area in the piedmont of Santiago, Chile (Romero et al., 1999; Romero and Vasquez 2005; Romero et al., 2010; Pavez et al., 2010; Banzhaf et al., 2013). The catchment has an area of $6.5 \mathrm{~km}^{2}$ and elevations range between 788 and $1310 \mathrm{~m}$. The geology is composed of permeable layer of fluvial deposits with andesitic rocks in the 
460

461

462

463

464

465

466

467

468

469

470

471

472

473

474

475

476

477

478 impermeable bottom. There is an unconfined aquifer with shallow depths in the upper portion of the catchment and larger depths in the lowest part. The natural area is covered by native vegetation (51\%) and the urban area covers the remaining $49 \%$.

The land use map was generated using information provided by the Chilean Areal Photographical Service and the Municipal Master Plan (Municipalidad de Lo Barnechea, 2012) whereas soil types and geology information were obtained from technical studies (DGA-AC, 2000; DGA-Arrau, 2008). Contours every 1 and $2.5 \mathrm{~m}$ and 1:2,500 and 1: 5,000 maps were available from DOH-EIC (2004) for the urban and natural portions of the catchment, respectively. Finally, the channelized network was identified from field surveys, and information provided by DOH-CADE (2001) and DOH-EIC (2004).

\subsubsection{Mercier catchment, Lyon (France)}

The Mercier catchment (Fig. 11b) is part of the Yzeron peri-urban watershed (150 $\mathrm{km}^{2}$ ) located southwest of Lyon, France. It has an area of $6.8 \mathrm{~km}^{2}$ and elevations range between 300 and $785 \mathrm{~m}$. The geology consists mainly of gneiss and granite, and soils are quite shallow, especially in upslope areas, leading to an overall low water storage capacity. Fifty percent of its area is for agriculture, $40 \%$ is covered by forests, and $10 \%$ is either urban or impervious (Braud et al., 2013).

The available information includes a detailed land use map obtained by manual digitalization (Jacqueminet et al., 2013), a pedology map (SIRA, 2011), a geology map (BRGM, 2011), a 2 m DEM (Sarrazin, 2012), a sub-catchment map generated using the method proposed by Jankowfsky et al. (2013), maps with ditches (Jankowfsky, 2011), and the sewer network provided by the Syndicat Intercommunal pour l'Aménagement de la Vallée de l'Yzeron.
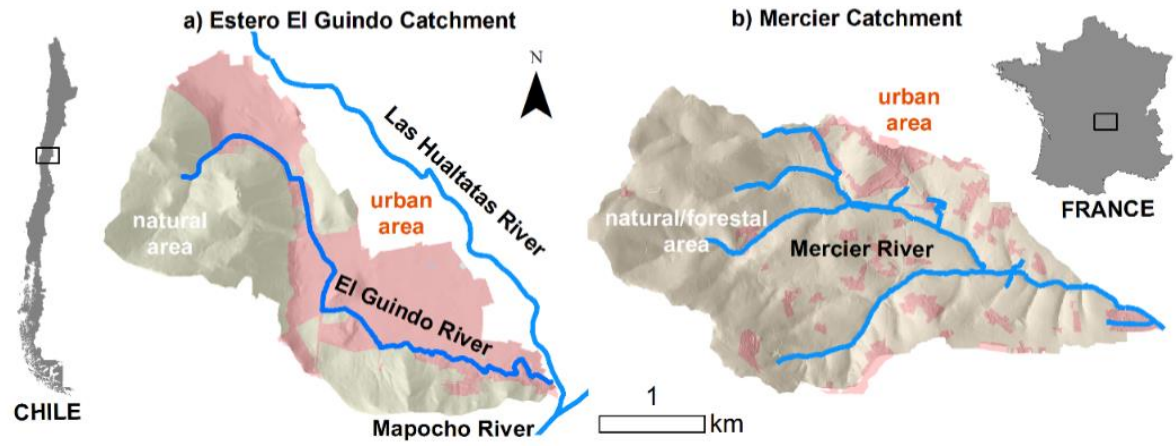
485

486

487

488

489

490

491

492

493

494

495

496

497

498

499

500

501

502

503

504

505

506

507

508

509

510

511

512

513

514

Figure 11. Study areas. a) Estero el Guindo Catchment, Chile, and b) Mercier

\section{Catchment, France.}

\subsection{Modeling meshes and associated drainage networks}

In this application, three meshes are defined:

- Initial Mesh (IniM): this mesh is obtained from intersecting the land use, soil type, sub-catchments and geology layers, but without applying step B2 on HRUs. CI and $F F$ values for this mesh are not restricted, and thus no correction to the mesh elements is implemented.

- Reference Mesh (RefM): this mesh was created using high values of the geometric indexes, i.e. $C I_{\min }=0.975, F F_{\min }=0.5$, and $A_{\max }=2$ ha. This is the best model mesh to be obtained from the available information, which allows the best topographic fidelity while avoiding topological problems. This mesh ensures a high degree of segmentation and significantly increases the number of final elements.

- Recommended Mesh (RecM): This mesh is obtained when using the default values of $C I_{\min }=0.75, F F_{\min }=0.20$ and $A_{\max }=2$ ha. This mesh is a compromise between the initial and reference meshes. It relies on $C I$ and $F F$ values that allow getting well-shaped elements, without significantly increasing their number.

\subsection{Characterization and assessment of the meshes and drainage networks}

3.3.1. Width and area functions

To characterize the drainage network extracted from each mesh, we use the width function $W(x)$ and area function $A(x) . W(x)$ corresponds to the number of drainage segments located at a given distance $x$ from the catchment outlet along the drainage network, whereas $A(x)$ is the portion of contributing area associated to this flow distance $x$ (Rodriguez-Iturbe and Rinaldo, 1997). Both $W(x)$ and $A(x)$ allow the characterization of the arrangement of flow paths and contributing areas in the catchment, which have strong implications on its hydrologic response (Rodríguez-Iturbe and Rinaldo, 1997). Indeed, $W(x)$ has previously been used to compare drainage network representations (Richards-Pecou, 2002; Moussa, 2008; Rodriguez et al., 2013; Sanzana et al., 2013), and to assess the effect of urbanization 
on the drainage network structure and potential impacts in the resulting hydrograph response (e.g., Smith et al., 2002; Gironás et al., 2009; Ogden et al., 2011).

In particular, we compare $W(x)$ and $A(x)$ of the IniM and RecM against the RefM to identify the locations and spatial scales at which the drainage networks associated with the different meshes differ. To assess the goodness-of-fit against the RefM, we use the Mean Absolute Error (MAE) and the Nash-Sutcliffe efficiency coefficient $\left(C_{N S}\right.$, Nash and Sutcliffe, 1970). The MAE is a residual measure to evaluate the goodness-of-fit in the units of the variable (Bennet et al., 2013), whereas the $C_{N S}$ is a relative error measure, which combines the correlation coefficient and observed and simulated means and standard deviations, to assess similarities in the overall function patterns (Legates and McCabe, 1999; Bennet et al., 2013). Values of $C_{N S}<1$ are associated with differences in the connectivity of the modeling meshes.

Because both $W(x)$ and $A(x)$ allow reducing the $2 \mathrm{D}$ drainage structure to a $1 \mathrm{D}$ mathematical function, they can be analyzed and compared using power spectral analysis. This analysis quantifies the distribution of power per unit frequency of discrete series, and is a useful tool to get information about their structure in the frequency domain. Such analysis has been previously applied to $W(x)$ and/or $A(x)$ (Rodríguez-Iturbe and Rinaldo, 1997; Veneziano et al., 2000; Richards-Pecou, 2002; Puente and Sivakumar, 2003; Moussa, 2008; Sanzana et al., 2013). For each of the three meshes, we compare the cross power spectral density (CPSD) of $W(x)$ (and $A(x)$ ) against that of $W(x)$ (and $A(x)$ ) of the RefM. The CPSD is the power spectral of the cross-covariance between two series (Shynk, 2012), which allows quantifying the power shared by a given frequency for the two series. Hence, it can be used to identify at which spatial scales $W(x)$ (and $A(x)$ ) of the IniM and RecM differ from $W(x)$ (and $A(x)$ ) of the RefM. Note that the CPSD of the same series is simply the power spectral density of the series. All the CPSD were computed using Matlab ${ }^{\circ}$.

\subsubsection{Instantaneous Unit Hydrograph (IUH)}

The basin geomorphology has been proven to be closely linked to its hydrologic response (Rodriguez-Iturbe and Rinaldo, 1997). In particular, $A(x)$ incorporates some essential characters of the hydrologic response because the travel time from the subareas in the catchments is related to the flow distance to be traversed. Thus, by normalizing $A(x)$ to ob- 
546

547

548

549

550

551

552

553

554

555

556

557

558

559

560

561

562

563

564

565

566

567

568

569

570

571

572

573

tain a unit area under the curve, and defining constant overland and channelized flow velocities, the spatial scale of $A(\mathrm{x})$ can be transformed into a temporal scale to generate an instantaneous unit hydrograph (IUH), i.e. the hydrologic response of the basin when represented as a linear system. This transformation has been implemented elsewhere in the literature (e.g. Rinaldo et al. 1995, Morrison and Smith, 2001, Smith et al., 2005; Gironás et al. 2009) and is proposed here to better understand the hydrologic impacts of the catchment representation using different modeling meshes computed by Geo-PUMMA. Following what is proposed by the UDFCD (2006), for Estero El Guindo we adopted a velocity $\mathrm{V}_{\mathrm{H}}=$ $0.75 \mathrm{~m} / \mathrm{s}$ for natural hillslopes or HRU (mean slope $34 \%$ ), a velocity $\mathrm{V}_{U}=0.27 \mathrm{~m} / \mathrm{s}$ for urban areas or UHE (mean slope $7 \%$ ) and a velocity $\mathrm{V}_{\mathrm{Ch}}=2.2 \mathrm{~m} / \mathrm{s}$ for the channelized network (mean slope 3\%, mixed natural/concreted channel). For the Mercier we adopted values of $\mathrm{V}_{\mathrm{H}}=0.27 \mathrm{~m} / \mathrm{s}$ (mean slope $13 \%$ ), $\mathrm{V}_{\mathrm{U}}=0.60 \mathrm{~m} / \mathrm{s}$ (mean slope $8 \%$ ) and $\mathrm{V}_{\mathrm{Ch}}=1.85 \mathrm{~m} / \mathrm{s}$ (mean slope 9\%, mostly natural channel).

\subsubsection{Discretization error metric}

Finally, we also use the sub-basin discretization error metric $\Delta L_{s}$ associated with a certain schematic representation $s$ (Liu et al., 2016) to compare IniM and RecM against RefM. $\Delta L_{s}$ is given by:

$$
\Delta L_{s}=L_{o}-L_{s}=\frac{\sum_{i=1}^{n} A_{i o} L_{i o}}{\sum_{i=1}^{n} A_{i o}}-\frac{\sum_{j=1}^{m} A_{j s} L_{j s}}{\sum_{j=1}^{m} A_{j s}}
$$

where $L_{o}$ and $L_{s}$ are the area-weighted in-channel routing lengths of the reference schematic representations $o$ and the representation $s$, and $A_{i o}\left(A_{j s}\right)$ is the areas contributing to the routing channel $i(j)$ of representation $o(s)$, whose length is $L_{i o}\left(L_{j s}\right)$. Although originally proposed for channelized network, this error metric can be used with meshes in which the different subareas have their corresponding drainage segment. Note that $\Delta L_{s}$ is a priori discretization error metric to estimate the hydrologic information loss by any discretization scheme as compared to a reference discretization (Liu et al., 2016). Hence, this metric complements the computation and analysis of the IUH in quantifying the hydrologic impact of different terrain representations without running a comprehensive hydrologic model. 


\section{RESULTS AND DISCUSSION}

\subsection{Main characteristics of the various modeling meshes}

Fig. 12 shows the three meshes generated for the Estero El Guindo catchment (Fig. 12a) and Mercier catchment (Fig. 12b). Grey lines represent the initial polygon segmentation (IniM), red lines the recommended mesh (RecM), and black lines the reference mesh (RefM). The corresponding drainage networks of El Guindo and Mercier are presented in Fig. 13. For each mesh, the drainage density $\left(D_{d}\right)$, defined as the ratio between the total length of the drainage network and the total area of the catchment, was computed (Table 2). For the Estero El Guindo, the segmentation procedure increases $D_{d}$ from $24.2 \mathrm{~km} / \mathrm{km}^{2}$ (IniM) to $32.9 \mathrm{~km} / \mathrm{km}^{2}$ (RefM), while for RecM, $D_{d}=26.2 \mathrm{~km} / \mathrm{km}^{2}$. For the Mercier catchment, the segmentation procedure increases the drainage density from $23.6 \mathrm{~km} / \mathrm{km}^{2}$ (IniM) to $31.6 \mathrm{~km} / \mathrm{km}^{2}$ (RefM), while for RecM, $D_{d}=26.4 \mathrm{~km} / \mathrm{km}^{2}$. In both cases, $D_{d}$ of the RecM increases by $\sim 10 \%$ as compared to the IniM. This increase is $\sim 30 \%$ for the highly detailed segmentation of the referenced mesh. Thus, RefM improves the representation of flow paths without increasing significantly the drainage density of the initial mesh. The segmentation procedure increases the drainage density of both catchments as the final number of hydrological response units also grows up. In addition, the increase of hydrological connectivity allows avoiding topological problems in the drainage network, due to the improvement of the flow paths representation.

Table 2 summarizes the main characteristics of the HRUs for each mesh, including their number, minimum, maximum and average areas $\left(A_{\min }, A_{\max }, A_{\text {ave }}\right)$, and the number of well-shaped HRUs for which $C I_{\min }>0.75$ and $F F_{\text {min }}>0.20$ (i.e. $\mathrm{HRU}_{\mathrm{FF}>0.2}$ and $H R U_{\mathrm{Cl}>0.75}$ ). Furthermore, regardless of the mesh, there are 2169 UHEs for El Guindo catchment and 290 for the Mercier catchment. The UHEs are considered as well-shaped elements, so they are preserved in all meshes. The segmentation of non-convex, thin and very large HRUs produces meshes RecM and RefM that are more homogeneous than IniM, as reflected by the increase in $\mathrm{HRU}_{\mathrm{FF}>0.2}$ and $\mathrm{HRU} \mathrm{Cl}_{\mathrm{C}>0.75}$. Although in some cases the initial percentage of well-shaped elements is high (e.g., IniM Mercier $\mathrm{HRU}_{\mathrm{Cl}>0.75}=99 \%$ ), they can be relevant in terms of area, so they must be included and improved to avoid connectivity distortions in the drainage networks. Such improvement ensures a more representative overland flow 
605 connectivity. For example, the segmentation removes long streets acting like walls that 606 artificially interfere the flow routing (Jankowfsky, 2011). Overall, Geo-PUMMA creates a 607 good quality mesh and a representative drainage network that can be useful for any 608 hydrological model applied to urban and peri-urban landscapes.

609

a) El Guindo

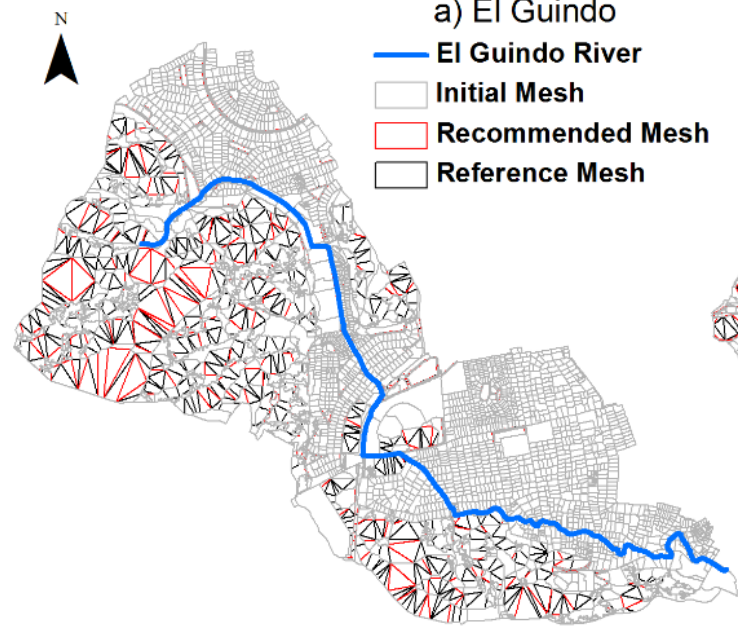

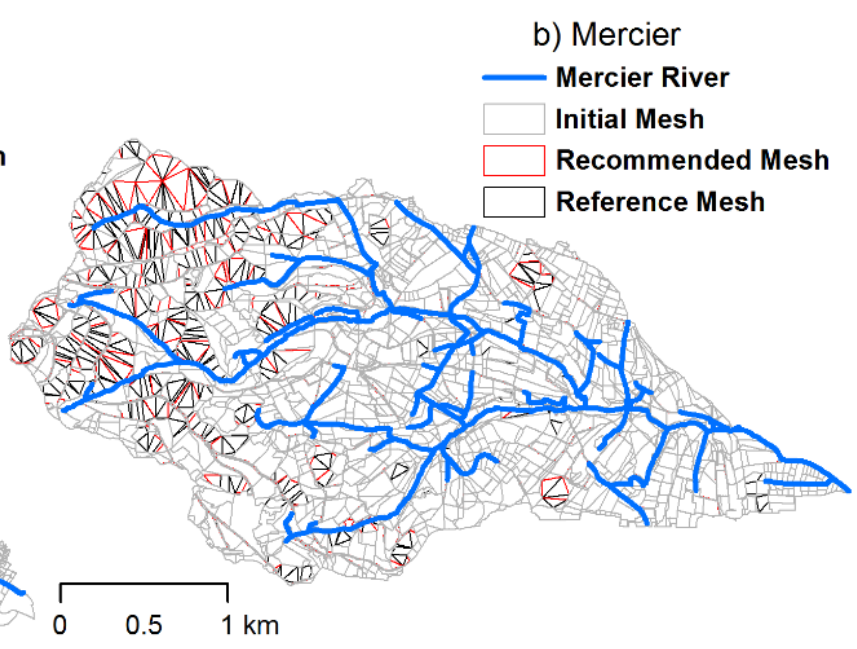

b) Mercier Initial Mesh Recommended Mesh Reference Mesh

Figure 12. Modeling meshes for El Guindo (a) and Mercier (b) catchments: Initial (grey), Recommended (red), and Reference (black) segmentation units are identified 
Table 2. Main characteristics of the Initial Mesh (IniM), Recommended Mesh (RecM)

616

\begin{tabular}{lccccccc}
\hline Mesh & $\mathrm{D}_{\mathrm{d}}\left(\mathrm{km} / \mathrm{km}^{2}\right)$ & $\mathrm{HRU}$ & $\mathrm{A}_{\min }\left(\mathrm{m}^{2}\right)$ & $\mathrm{A}_{\max }\left(\mathrm{m}^{2}\right) \mathrm{A}_{\mathrm{ave}}\left(\mathrm{m}^{2}\right)$ & $\mathrm{HRU}_{\mathrm{FF}>0.2}$ & $\mathrm{HRU}_{\mathrm{C}>0.75}$ \\
\hline IniM El Guindo & 24.2 & 2,057 & 0.1 & 243,133 & 2,119 & $767(83.8 \%)$ & $737(80.5 \%)$ \\
RecM El Guindo & 26.2 & 2,016 & 10 & 38,663 & 1,862 & $1,270(94.9 \%)$ & $1,145(85.5 \%)$ \\
RefM El Guindo & 32.9 & 3,749 & 10 & 29,466 & 1,427 & $2,370(98.4 \%)$ & $2,229(92.6 \%)$ \\
\hline IniM Mercier & 23.6 & 915 & 2.0 & 192,144 & 3,118 & $1,644(79.9 \%)$ & $2,037(99.0 \%)$ \\
RecM Mercier & 26.4 & 1338 & 10 & 20,275 & 2,354 & $1,849(91.7 \%)$ & $1,998(99.1 \%)$ \\
RefM Mercier & 31.6 & 2408 & 10 & 19,337 & 1,811 & $3,480(92.8 \%)$ & $3,745(99.8 \%)$
\end{tabular}

617

618

619

620

621

622

623

624

625

626

627

628

629

630

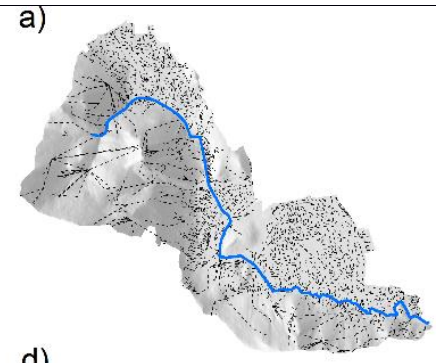

d)

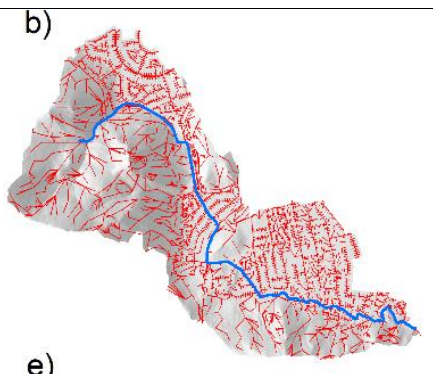

e)

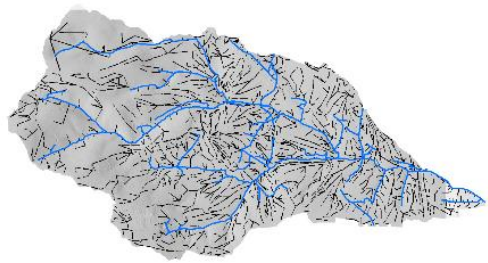

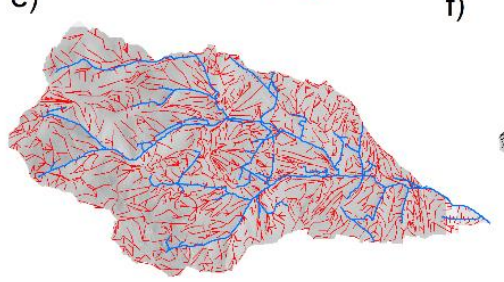

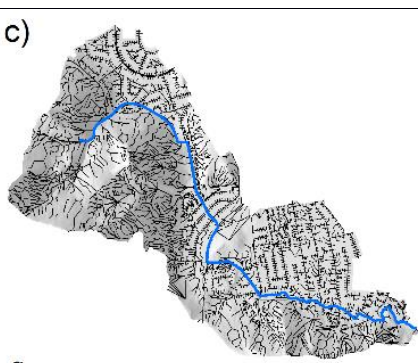

f)

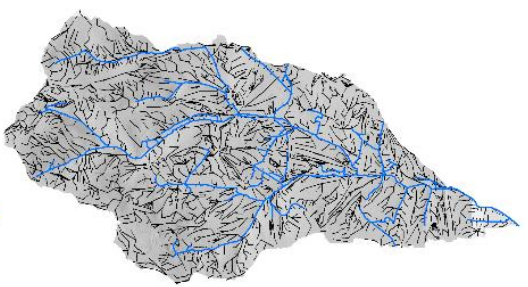

Figure 13. Initial (a), Recommended (b), and Reference (c) Drainage Networks of El Guindo. Initial (d), Recommended (e), and Reference (f) Drainage Networks of Mercier

4.2. Assessment and comparison of drainage networks

4.2.1. Width and area functions

Fig. 14 compares $W(x)$ and $A(x)$ of each mesh and catchment. $W(x)$ of IniM significantly differs from that of the RefM for Estero El Guindo $\left(C_{N S \text { ref-ini }}=0.463\right.$ and MAE $r_{\text {ref-ini }}=6.95$, Fig. 14a $)$ and Mercier $\left(C_{N S \text { ref-ini }}=0.575\right.$ and $\mathrm{MAE}_{r e f-i n i}=7.41$, Fig. 14b), whereas such difference is much less substantial when comparing RecM and RefM, both in Estero El Guindo $\left(C_{N S \text { ref-rec }}=0.901\right.$ and $\mathrm{MAE}_{\text {ref-rec }}=2.22$, Fig. $\left.14 \mathrm{a}\right)$ and Mercier $\left(C_{N S \text { ref-rec }}=0.768\right.$ and MAE $_{\text {ref-rec }}=6.27$, Fig.14b). In the case of the Mercier catchment, $W(x)$ of IniM and RecM considerably differ in the upper part (from $x=3500$ to $5200 \mathrm{~m}$, Fig. 14b), as the 
631 segmented HRUs are mainly located in natural sections at the foothill area of the catchment 632 (Fig.12b).

634 Guindo $\left(C_{N S \text { ref-ini }}=0.080\right.$ and MAE ${ }_{r e f-i n i}=0.023$, Fig. $\left.14 \mathrm{c}\right)$ and Mercier $\left(C_{N S \text { ref-ini }}=0.313\right.$

635 and MAE ref-ini $=0.028$, Fig.14d). This poor representation of the reference $A(x)$ occurs

636 because there are large areas not segmented in the IniM that contribute directly to specific

637 locations in the drainage network, which in turns causes major fluctuations of the IniM $A(x)$

638 functions for both catchments (Fig. 14c, 14d). On the other hand, $A(x)$ of RecM and RefM

639 are more similar $\left(C_{N S \text { ref-rec }}=0.120\right.$ and $\mathrm{MAE}_{\text {ref-rec }}=0.017$ for El Guindo, Fig. $14 \mathrm{c}$ and $C_{N S}$

640 ref-rec $=0.446$ and $\mathrm{MAE}_{\text {ref-rec }}=0.023$ for Mercier, Fig.14d). Although these $C_{N S}$ values are

641 not very high, the overall shape of $A(x)$ resembles better than of the RefM, particularly as

642 the large fluctuations previously identified for the IniM are not observed here. Note that 643 improvements associated with the RecM in Estero El Guindo take place across different 644 values of $x$, as bad-shaped elements were homogeneously located throughout the 645 catchment. In the case of Mercier, bad-shaped elements were mostly located in the upper 646 zone, so most of the improvements in $W(x)$ and $A(x)$ are observed for the largest values of $x$.
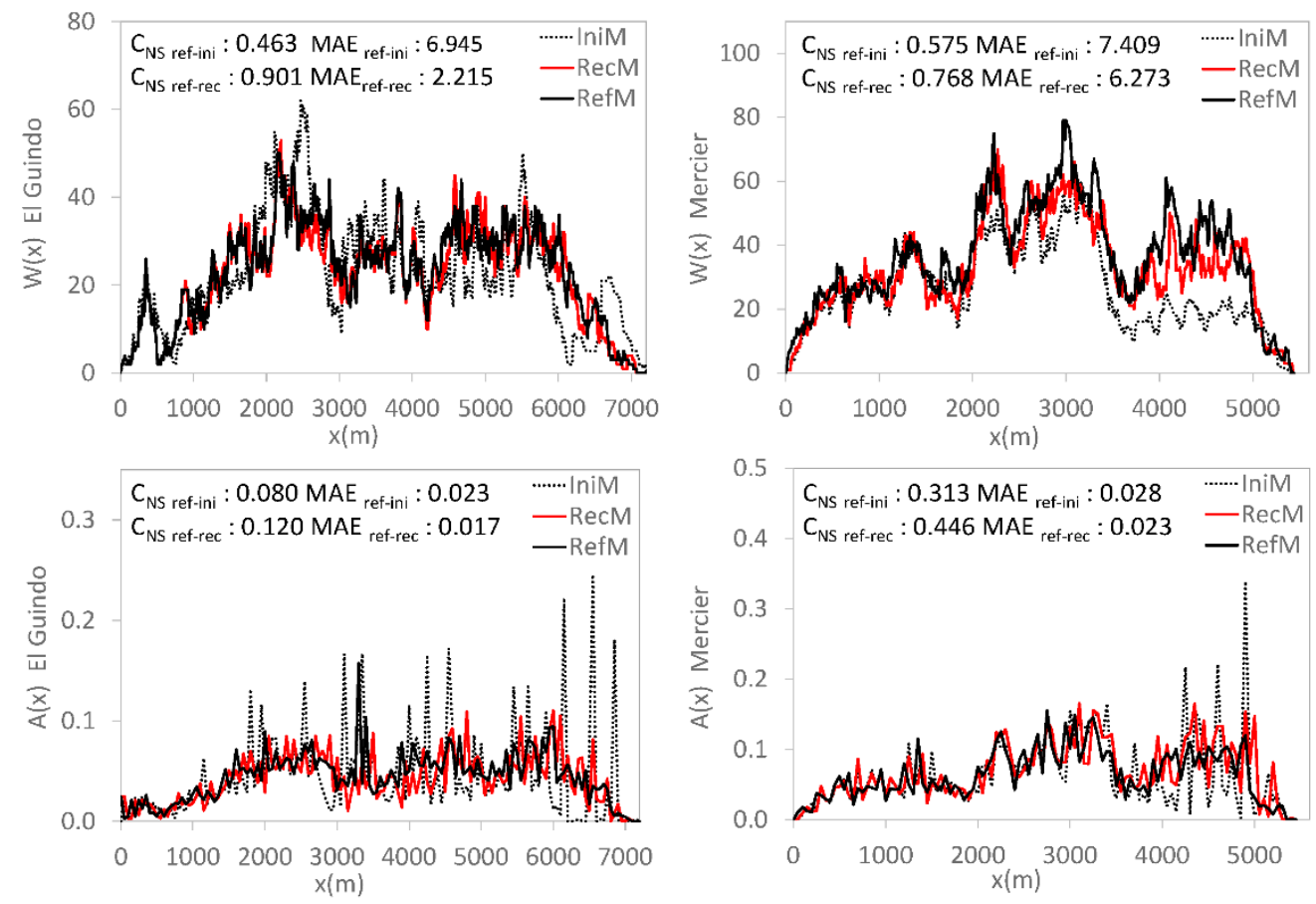
648

649

650

651

652

653

654

655

656

657

658

659

660

661

662

663

664

665

666

667

668

669

670

671

672

673

674

675

676

677

678

Figure 14. $W(x)$ of El Guindo (a) and Mercier (b) catchments. $A(x)$ of El Guindo (c) and Mercier (d) catchments. Each panel shows the results for the IniM (grey dotted line), RecM (continuous red line), and RefM (continuous black line).

Fig. 15 shows the CPSD of $W(x)$ and $A(x)$ for both catchments. Here we define $\mathrm{P}_{\text {RefM,RefM }}$ as the CPSD between RefM and itself, $\mathrm{P}_{\text {RefM,IniM }}$ as the CPSD between RefM and IniM, and $\mathrm{P}_{\mathrm{RefM}, \mathrm{RecM}}$ as the CPSD between RefM and RecM. The more similar to $P_{\text {RefM,RefM }}$ a cross-spectrum is, the more similar the corresponding $W(x)$ or $A(x)$ is to that of the Reference mesh. For $W(x)$ in the Estero El Guindo (Fig.15a), $\mathrm{P}_{\text {RefM,RefM }}$ and $\mathrm{P}_{\text {RefM,IniM }}$ differ at high frequencies with length scales of $\tau_{1} \approx 120 \mathrm{~m}$ or less, whereas $\mathrm{P}_{\text {RefM, RefM }}$ and

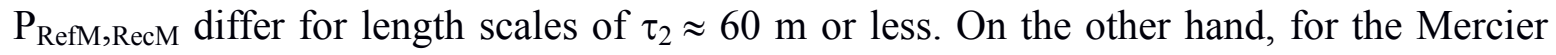
catchment (Fig.15b) $\mathrm{P}_{\text {RefM, RefM }}$ and $\mathrm{P}_{\text {RefM,IniM }}$ differ at high frequencies with length scales of $\tau_{1} \approx 80 \mathrm{~m}$ or less, whereas $\mathrm{P}_{\text {RefM,RefM }}$ and $\mathrm{P}_{\text {RefM,RecM }}$ differ for length scales of $\tau_{2} \approx 60 \mathrm{~m}$ or less. Hence, in both catchments, the results from the CPSD analysis confirm that $W(x)$ of the RecM is better than that of the IniM in resembling $W(x)$ of the RefM at smaller scales. This improvement is relevant as small-scale features are fundamental in explaining the different mechanisms influencing the hydrologic response of urban catchments (Rossel et al., 2014). Moreover, previous studies concluded that high-frequency components of $W(x)$ may be useful for classification of river network topology and regionalization of floods (Richards-Pecou, 2002; Lashermes and Foufoula-Georgiou, 2007, Moussa, 2008).

For $A(x)$ in the Estero El Guindo (Fig.15c), $\mathrm{P}_{\text {RefM,RefM }}$ and $\mathrm{P}_{\text {RefM,IniM }}$ also differ at high frequencies with length scales of $\tau_{1} \approx 150 \mathrm{~m}$ or less, whereas $\mathrm{P}_{\mathrm{RefM}}$,RefM and $\mathrm{P}_{\mathrm{RefM}}$,RecM differ for length-scales of $\tau_{2} \approx 100 \mathrm{~m}$ or less. For the Mercier catchment (Fig.15d) $\mathrm{P}_{\text {RefM,RefM }}$ and $\mathrm{P}_{\text {RefM,Inim }}$ differ at high frequencies with length scales of $\tau_{1} \approx 150 \mathrm{~m}$ or less, whereas

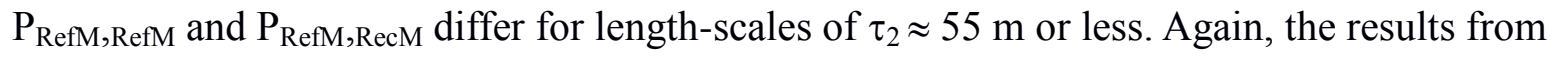
the CPSD analysis show that $A(x)$ of the RecM resembles better than of RefM at smaller scales than $A(x)$ of IniM.

Our results reinforce the idea that the main impacts associated with different terrain representations are observed at small length-scales, typical of residential lots and streets (Sanzana et al., 2013), and that the recommended mesh to represent the terrain is able to minimize these impacts while being efficient in terms of computing time cost. Indeed, using 
679

680

681

682

683

684

685

686

687

688

689

690

691

692

693

694

695

geometrical restrictions to generate the terrain meshes for both catchments improved the representation of the drainage network.
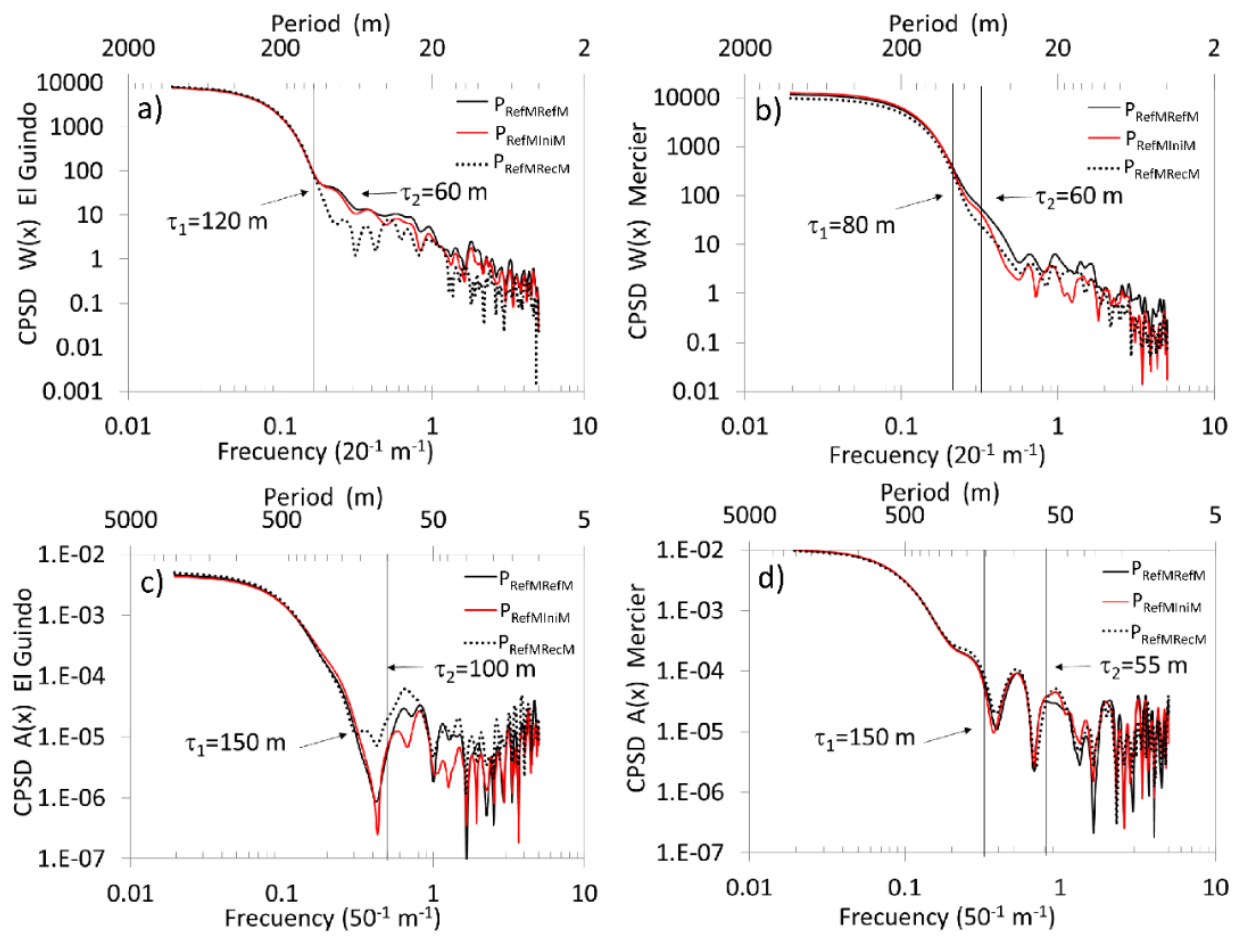

Figure 15. CPSD of $W(x)$ for El Guindo (a) and Mercier (b) catchments. CPSD of $A(x)$ for EI Guindo (c) and Mercier (d) catchments. Each panel shows the IniM (grey dotted line), RecM (continuous red line), and RefM (continuous black line)

\subsubsection{IUH extracted from hydrological meshes}

The IUHs computed from $A(x)$ of the different drainage networks are presented for El Guindo (Fig. 16a) and the Mercier (Fig. 16b) catchments. As expected, all the hydrographs are positively skewed, and the degree of similarity among them is much higher than for the case of $A(x)$, regardless the drainage network from which they come. Nonetheless, for both catchments the IUH for RecM resembles much more that of the RefM than the IniM $\left(C_{N S \text { ref-ini }}=0.476\right.$ vs. $C_{N S \text { ref-rec }}=0.845$ for El Guindo, and $C_{N S \text { ref-ini }}=$ 0.854 vs. $C_{N S \text { ref-rec }}=0.959$ for Mercier), as part of the fluctuations of $A(x)$ for IniM is transferred to the corresponding IUHs. 
696

697

698

699

700

701

702

703

704

705

706

707

708

709

710

711

712

713

714

715

716

717

718

719
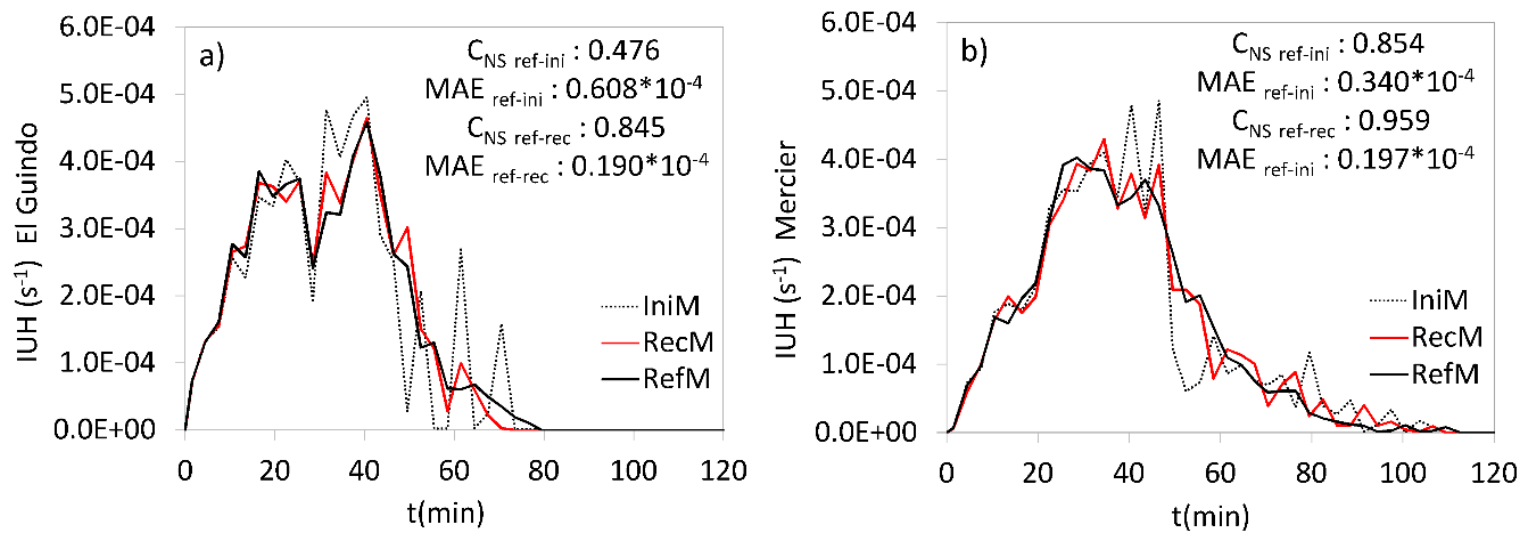

Figure 16. IUH derived from IniM, RecM and RefM for El Guindo (a) and Mercier (b) catchments.

\subsubsection{Discretization error metric}

After defining RefM as the reference schematic representation in Eq. (1), for each catchment we computed $\Delta L_{i n i}$ and $\Delta L_{r e c}$ of the IniM and RecM respectively. For the Estero El Guindo, $\Delta L_{i n i}=140-57=83 \mathrm{~m}$ and $\Delta L_{r e c}=82-57=26 \mathrm{~m}$, whereas for the Mercier catchment $\Delta L_{i n i}=91-67=24 \mathrm{~m}$ and $\Delta L_{r e c}=77-67=10 \mathrm{~m}$. Hence, for both catchments the recommended mesh produces a lower discretization error metric, which is in agreement with the better resemblance with the reference IUH achieved using the recommended mesh.

\subsection{Qualitative comparison of Geo-PUMMA with a classical raster approach}

Finally, we assessed the results from Geo-PUMMA by comparing the terrain generated for both catchments with that produced by HRU-DELIN (Tilmant et al., 2015), a tool that uses the raster approach implemented in GRASS-HRU (Schwartze, 2008). The implementation of HRU-DELIN used a high resolution $2 \mathrm{~m} \mathrm{DEM}$, and considered a minimum area threshold of $10 \mathrm{~m}^{2}$ for generating the HRU. For the upstream portion of El Guindo, Figs. 17a-c illustrate the HRU produced with HRU-DELIN, Geo-PUMMA and the corresponding aerial photograph, respectively, while Figs. $17 \mathrm{~d}-\mathrm{f}$ illustrate the same for the downstream portion of the catchment. Figs. 17 g-i and Figs. 17 j-1 present the same for the upstream and downstream portions of the Mercier catchment, respectively. Because it is a vectorial polygonal mesh generator, in both catchment some thin features (Figs. 17 a,g) or physical boundaries (Figs. $17 \mathrm{~d}, \mathrm{j}$ ) not well captured by HRU-DELIN, are preserved by 
721 generated by HRU-DELIN for both catchments (over 30,000 units), some land use features

722 are lost. Geo-PUMMA can represent the terrain with a much more reasonable number of

723 HRU ( 2,000 HRUs) without major losses of land use features. Overall, these results show

724 that Geo-PUMMA is an appropriate tool to represent urban and peri-urban terrains, while

725 tools such as HRU-DELIN are more suitable for representing medium and regional scales

726 in rural or natural catchments.
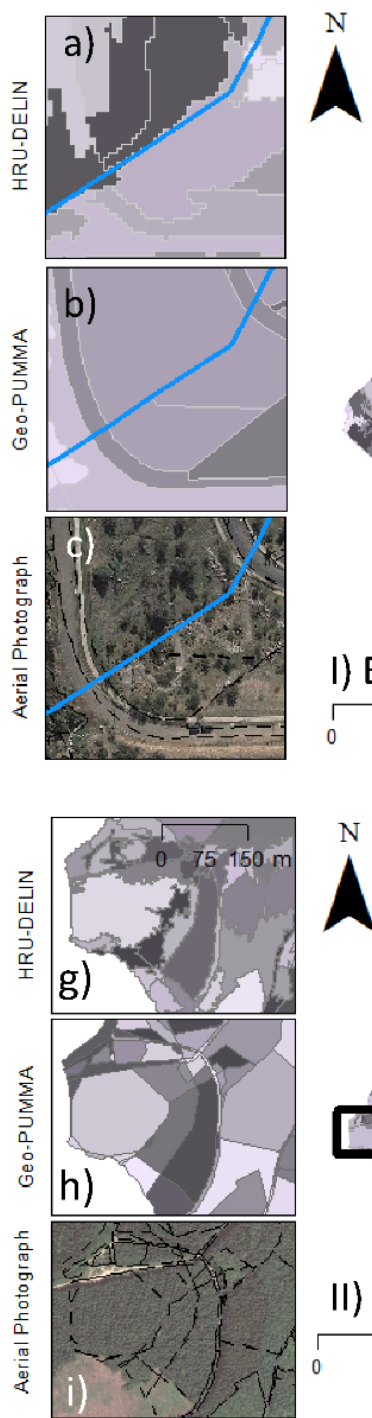
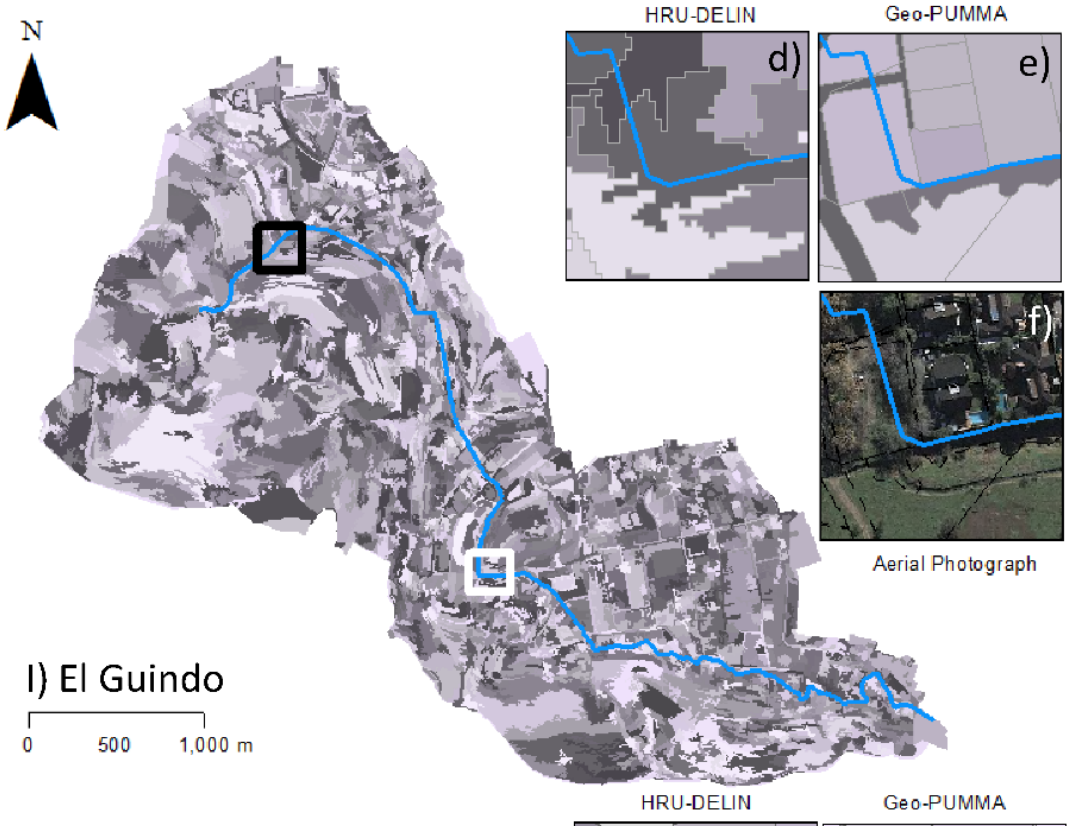

727

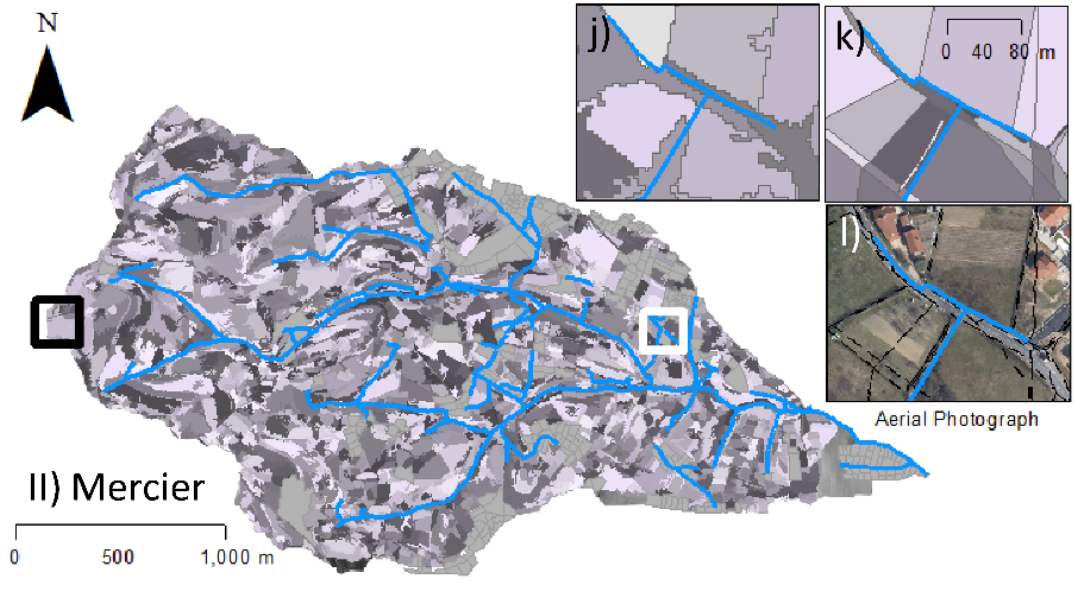

Figure 17. HRU generated using HRU-DELIN (raster approach) and Geo-PUMMA 729 (vectorial approach) in EI Guindo (I) and Mercier (II) catchments. Comparisons of 730 HRU produced with both tools and the corresponding aerial photograph are 
731

732

733

734

735

736

737

738

739

740

741

742

743

744

745

746

747

748

749

750

751

752

753

754

755

756

757

758

759

760

761

presented for upstream (a, b, c, g, h, i) and downstream (d, e, f, j, k, l) portions of both catchments.

\section{CONCLUSIONS AND FUTURE WORK}

This paper presents and describes Geo-PUMMA, a polygonal mesh generation tool for representing urban and peri-urban terrains and create the main inputs for distributed hydrological modeling. Geo-PUMMA considers the main physiographic units available in natural and urban landscapes, represented by means of Hydrological Response Units (HRUs) and Urban Hydrological Elements. The tool allows the generation of high quality polygonal meshes in which the numerous bad-shaped units, created by the initial intersection of GIS maps (land use, soil type, geology, river network), are improved. In particular, the tool succeeds in segmenting non-convex, thin and large elements and assigning more homogeneous properties to the different HRUs in the mesh. Geo-PUMMA represents urban and natural elements and extracts the hydrological interfaces and the drainage network with routing scripts. The generated vectorial mesh and corresponding databases provide useful information for any distributed hydrological model that requires a detailed representation of urban and peri-urban terrains. Geo-PUMMA is a computer-aided, semi-automatic tool, so the active involvement of the modeler is required to obtain good results.

Geo-PUMMA was applied to two peri-urban catchments located in different geographical regions (El Guindo, Chile and Mercier, France). We generated three spatial meshes with different degrees of segmentation, defined by threshold values of geometric constraints (i.e convexity index $C I$, form factor $F F$ and maximum HRU area $A_{\max }$ ). The quality of the topography and drainage network representation increased with the degree of segmentation, but the computing-time grew as well. For both catchments a recommended mesh was identified, which represented the terrain well without highly increasing the number of HRUs. In addition, this mesh was demonstrated to provide a hydrologic connectivity very similar to that obtained for the most detailed possible representation. This mesh considered threshold values of $C I=0.75, F F=0.2$ and $A_{\max }=2$ ha, which are recommended for future applications of Geo-PUMMA. Overall, the application to both catchments shows the flexibility of the tool with different geographical conditions. 
Other examples of decomposition of non-convex polygons into "approximately 763 convex" elements implemented by Lien and Amato (2006) (ACD algorithm) and Liu et al. 764 (2014) (DuDe algorithm) only consider convexity criterion strictly. It would be interesting 765 to compare these geometrical algorithms against the one proposed in Geo-PUMMA, in 766 order to evaluate its possibility to use other geometrical criteria. Moreover, a more detailed 767 analysis could be performed to better assess and justify the threshold values of $C I$ and $F F$ 768 here proposed, and to improve the computational complexity of the geometrical algorithms 769 developed in Geo-PUMMA.

770

771 ACKNOWLEDGEMENTS

772 This work was developed within the framework of Project MAPA (IDRC 107081773 001) and Project ECOS-CONICYT C14U02. Funding from Projects FONDECYT $774 \quad N^{\circ} 1131131$, CEDEUS (FONDAP 15110020), FONDECYT ENL009/15 and IRSTEA-Lyon 775 are also acknowledged. Finally Jorge Gironás acknowledge CIGIDEN (FONDAP 776 15110017). The Mercier catchment is part of OTHU (Observatoire de Terrain en 777 Hydrologie Urbaine). This work was partially developed within the framework of the Panta 778 Rhei Research Initiative of the International Association of Hydrological Sciences. 
779 APPENDIX 1: List of additional GRASS and Geo-MHYDAS commands

780 The following are the additional GRASS and Geo-MHYDAS scripts of optional or 781 compulsory use.

782

783 GRASS GIS Commands

v.generalize: Vector based generalization. Used to simplify contour and vertexes necessary to represent an irregular shape unit (Optional Tool).

v.clean: Toolset for cleaning topology of vector map. Used to clean small areas (Optional Tool).

\section{$\underline{\text { Geo-MHYDAS Commands }}$}

790 m.snaplp: Adjusting geometry of linear features. Used to adjust river polyline to the closet boundaries (Optional Tool).

m.seg: Overlaying geographical objects. Used to create the first intersection of polygons and polylines features (Compulsory Tool).

m.dispolygseg: Selective dissolving small areal features. Used to dissolve areas with area lower than certain threshold (Optional Tool).

m.sliverpolygseg: Selective dissolving sliver areal features. Used to dissolve thin and long units (Optional Tool). 
798 APPENDIX 2: Form Factor segmentation script (p.form_factor.py)

799 1.- For each polygon $P$ with $F F \leq F F_{\text {min }}$

$800 \quad$ 2.- $\quad$ Split boundaries inserting vertex $d_{\max }=5 \mathrm{~m}$

801 3.- $\quad$ Apply Triangle

802 4.- While $\mathrm{P}$ has triangles not yet dissolved

803 5.-

Select triangle with the largest area

804 6.-

Select triangle neighbor with the largest area and create new group $P$,

805 7.-

While $F F$ of $P^{\prime} \geq F F_{\text {min }}$

806 8.-

Search the neighbor triangles with the largest area

807 9.-

Dissolve boundaries of this group

808 10.-

Compute the FF of this new group

809 11.-

end while

$810 \quad 12 .-$

Update $P=P-P^{\prime}$

811 13.- $\quad$ end While

812 14.- Dissolve areas $<$ area threshold

813 15.- end For 
814 APPENDIX 3: OLAF Algorithm (p.olaf.py)

815 1.- For each sub-catchment S

816 2.- $\quad$ Find isolated URH or UHE in the border (only with one neighbor)

817 3.- Connect them with nearest neighbor

818 4.- $\quad$ Find the URH or UHE which share a boundary with channelized system

819 5.- $\quad$ Connect the URH or UHE with channelized drainage

820 6.- $\quad$ Find the highest URH or UHE

821 7.- $\quad$ Connect it with the lowest neighbor until reaching the channelized system

822 8.-

823 9.-

824 10.-

825 11.-

826 12.-

827 13.-
If it does not reach the channelized drainage

Go back one neighbor element upstream

Connect it whit the second lowest neighbor

If there is a loop

Go back to the unit upstream the loop

Connect it with the second lowest neighbor

828 14.- Collect all the OLAF path-ways 


\section{REFERENCES}

Banzhaf, E., Reyes-Paecke, S., Müller, A., Kindler, A., 2013. Do demographic and land-use changes contrast urban and suburban dynamics? A sophisticated reflection on Santiago de Chile. Habitat International. 39, 179-191. DOI: 10.1016/j.habitatint.2012.11.005

Bennett, N.D., Croke, G.F.W., Guariso, G., Guillaume, J.H.A., Hamilton, S.H., Jakeman, A.J., Marsili-Libelli, S., Newham, L.T.H., Norton, J.P., Perrin, C., Pierce, S.A., Robson, B., Seppelt, R., Voinov, A.A., Fath, B.D., Andreassian, V., 2013. Characterizing performance of environmental models. Environmental Modelling \& Software. 40, 1-20. DOI: 10.1016/j.envsoft.2012.09.011

Bhatt, G., Kumar, M., Duffy, C.J., 2014. A tightly coupled GIS and distributed hydrologic modeling framework. Environmental Modelling \& Software. 62, 70-84. DOI: 10.1016/j.envsoft.2014.08.003

Bocher, E. and Martin, J.Y., 2012. TAnaTo2: A tool to evaluate the impact of natural and anthropogenic artefacts with a TIN-based model, in Bocher, E., Neteler, M. (Eds,), Geospatial Free and Open Source Software in the 21st Century. Springer Berlin Heidelberg. pp. 63-85. DOI: 10.1007/978-3-642-10595-1_5

Booth, D.B. and Fischenich, C.J., 2015. A channel evolution model to guide sustainable urban stream restoration. Area. 47(4), 408-421. DOI: 10.1111/area.12180

Booth, D.B. and Henshaw, P. C., 2001. Rates of Channel Erosion in Small Urban Streams, in Wigmosta, M. S., Burges, S. J. (Eds.), Land Use and Watersheds: Human Influence on Hydrology and Geomorphology in Urban and Forest Areas, American Geophysical Union, Washington, D. C. 17-38. DOI: 10.1029/WS002p0017

Braud, I., Breil, P., Thollet, F., Lagouy, M., Branger, F., Jacqueminet, C., Kermadi, S., Michel, K., 2013. Evidence of the impact of urbanization on the hydrological regime of a medium-sized periurban catchment in France. Journal of Hydrology. 485, 5-23. DOI: 10.1016/j.jhydrol.2012.04.049.

Braud, I., Fletcher, T.D., Andrieu, H., 2013. Hydrology of peri-urban catchments: Processes and modelling. Journal of Hydrology. 485, 1-4. DOI: 10.1016/J.hydrol.2013.02.045 
BRGM, 2011. Bureau of Geological and Mining Research. URL: http://infoterre.brgm.fr/viewer/MainTileForward.do;jsessionid=C6247604415C79 ABC4729563FD5969E [In French, accessed 18.03.16]

Brossard, F., 2011. Automatisation du pretraitement des donnees spatiales pour la modelisation hydrologique distribuee en zone peri-urbaine [Automatization of preprocessing of spatial information for distributed hydrological modeling in periurban zones]. Rapport de Step 2AE. EPMI Ecole D’Ingenieurs. Cemagref-Lyon. 77 [In French].

DGA-AC, 2000. Modelo de simulación hidrológico operacional cuencas de los ríos Maipo y Mapocho [Hydrological modeling for management of Maipo and Mapocho Catchments]. Dirección General de Aguas, División de Estudios y Planificación, Ayala, Cabrera y Asociados Ingenieros Consultores Ltda. [In Spanish].

DGA-Arrau, 2008. Plan director para la gestión de los recursos hídricos cuenca del río Maipo: fase II actualización del modelo [Master Plan for water resources management of Maipo river: Second Step updating modeling]. Dirección General de Aguas, Ministerio de Obras Públicas de Chile. Arrau Ingeniería. [In Spanish].

DOH-CADE, 2001. Plan maestro de evacuación y drenaje de aguas lluvias del Gran Santiago [Urban Drainage and Stormwater Master Plan for the Metropolitan area of Santiago]. Dirección de Obras Hidráulicas, Ministerio de Obras Públicas de Chile. CADE Consultores en Ingeniería.[In Spanish].

Di Luzio, M., Srinivasan, R., Arnold, J.G., 2004. A GIS-coupled hydrological model system for the watershed assessment of agricultural nonpoint and point sources of pollution. Transactions in GIS. 8(1), 113-136. DOI: 10.1111/j.14679671.2004.00170.x

DOH-EIC, 2004. Diagnóstico y proposición plan maestro de manejo de cauces naturales, cuenca del río Mapocho hasta Estero las Hualtatas [Diagnostic and Master Plan proposal for the Management of Mapocho River and Estero Las Hualtatas]. Región Metropolitana. Dirección de Obras Hidráulicas, EIC consultores. [In Spanish].

Douglas, D.H. and Peucker, T.K., 1973. Algorithms for the reduction of the number of points required to represent a digitized line or its caricature. Cartographica: The 
International Journal for Geographic Information and Geovisualization. 10(2), 112122. DOI: 10.3138/FM57-6770-U75U-7727

Flügel, W.A., 1995. Delineating hydrological response units by geographical information system analyses for regional hydrological modelling using PRMS/MMS in the drainage basin of the River Bröl, Germany. Hydrological Processes. 9(3-4), 423436. DOI: 10.1002/hyp.3360090313

Fuamba, M., Branger, F., Braud, I., Sanzana Cuevas P., Sarrazin, B., Jankowfsky, S., 2015. Interest of spatially distributed data to evaluate the object-oriented PUMMA model on the semi-rural Mercier catchment (Yzeron basin, France), 36th IAHR World Congress, June 28-July 3 2015, Delft, The Hague, The Netherlands, 8 pp, http://89.31.100.18/ iahrpapers/80490.pdf

Geo-PUMMA $\quad$ Team, $2017 . \quad$ Geo-PUMMA Tutorial v.1. https://forge.irstea.fr/projects/geopumma [accessed 10.01.17]

Gironás J., Roesner L.A., Rossman L.A., Davis J., 2010. A new applications manual for the storm water management model (SWMM). Environmental Modelling \& Software. 25(6), 813-814. DOI: 10.1016/j.envsoft.2009.11.009.

Gironás, J., Niemann, J.D., Roesner, L.A., Rodriguez, F., and Andrieu, H., 2010. Evaluation of methods for representing urban terrain in storm-water modeling. Journal of Hydrologic Engineering. 15(1), 1-14. DOI: 10.1061/(ASCE)HE.19435584.0000142

Gironás, J., Niemann, J.D., Roesner, L.A., Rodriguez, F., Andrieu, H., 2009. A morphoclimatic instantaneous unit hydrograph model for urban catchments based on the kinematic wave approximation. Journal of Hydrology. 377, 317-334. DOI:10.1016/j.jhydrol.2009.08.030

GRASS Development Team, 2015. Geographic Resources Analysis Support System (GRASS) Software, Version 6.4. Open Source Geospatial Foundation. http://grass.osgeo.org [accessed 18.03.16]

Haunert, J.H. and Sester, M., 2008. Area collapse and road centerlines based on straight skeletons. GeoInformatica. 12(2), 169-191. DOI: 10.1007/s10707-007-0028-X 
918

919

920

921

922

923

924

925

926

927

928

929

930

931

932

933

934

935

936

937

938

939

940

941

942

943

944

945

946

947

948

Holmgren, P., 1994. Multiple flow direction algorithms for runoff modelling in grid based elevation models: an empirical evaluation. Hydrological processes. 8(4), 327-334. DOI: 10.1002/hyp.3360080405

Hu, X., Zhang, Z. and Tao, C.V., 2004. A robust method for semi-automatic extraction of road centerlines using a piecewise parabolic model and least square template matching. Photogrammetric Engineering \& Remote Sensing. 70(12), 1393-1398. DOI: 10.14358/PERS.70.12.1393

Jacqueminet, C., Kermadi, S., Michel, K., Béal, D., Gagnage, M., Branger, F., Jankowfsky, S. and Braud, I., 2013. Land cover mapping using aerial and VHR satellite images for distributed hydrological modelling of periurban catchments: application to the Yzeron catchment (Lyon, France). Journal of Hydrology. 485, 68-83. DOI:10.1016/j.jhydrol.2013.01.028

Jankowfsky, S., 2011. Understanding and modelling of hydrological processes in small peri-urban catchments using an object oriented and modular distributed approach. Application to the Chaudanne and Mercier sub-catchments (Yzeron Catchment, France). École Doctorale Terre, Univers, Environnement. l'Institut National Polytechnique de Grenoble. URL: http://tel.archives-ouvertes.fr/tel-00721988. [accessed 18.03.16]

Jankowfsky, S., Branger, F., Braud, I., Gironás, J. and Rodriguez, F., 2013. Comparison of catchment and network delineation approaches in complex suburban environments: application to the Chaudanne catchment, France. Hydrological Processes. 27(25), 3747-3761. DOI: 10.1002/hyp.9506

Jankowfsky, S., Branger, F., Braud, I., Rodriguez, F., Debionne, S., Viallet, P., 2014. Assessing anthropogenic influence on the hydrology of small peri-urban catchments: Development of the object-oriented PUMMA model by integrating urban and rural hydrological models. Journal of Hydrology. 517, 1056-1071. DOI: 10.1016/j.jhydrol.2014.06.034

Kass, M., Witkin, A., Terzopoulos, D., 1988. Snakes: Active contour models. International journal of computer vision. 1(4), 321-331. DOI: 10.1007/BF00133570

Lagacherie, P., Rabotin, M., Colin, F., Moussa, R.,Voltz, M., 2010. Geo-MHYDAS: a landscape discretization tool for distributed hydrological modeling of cultivated 
areas. Computers \& Geosciences. 36(8), 1021-1032. DOI: 10.1016/j.cageo.2009.12.005

Lashermes, B. and Foufoula-Georgiou, E., 2007. Area and width functions of river networks: New results on multifractal properties. Water resources research. 43(9), 1-19. DOI: 10.1029/2006WR005329.

Lashermes, B., Foufoula-Georgiou, E., Dietrich, W. E., 2007. Channel network extraction from high resolution topography using wavelets. Geophysical Research Letters. 34, L23S04. DOI:10.1029/2007GL031140.

Legates, D.R., McCabe, G.J., 1999. Evaluating the use of "goodness-of-fit" measures in hydrologic and hydroclimatic model validation. Water Resources Research. 35(1), 233-241. DOI: 10.1029/1998WR900018.

Lee, J.G. and Heaney, J.P., 2003. Estimation of urban imperviousness and its impacts on storm water systems. Journal of Water Resources Planning and Management. 129(5), 419-426. DOI: 10.1061/(ASCE)0733-9496(2003)129:5(419)

Leninisha, S. and Vani, K., 2015. Water flow based geometric active deformable model for road network. ISPRS Journal of Photogrammetry and Remote Sensing. 102, 140147. DOI:10.1016/j.isprsjprs.2015.01.013

Lien, J.-M. and Amato, N.M., 2006 Approximate convex decomposition of polygons. Computational Geometry Theory and Applications. 35(1), pp. 100-123. DOI:10.1016/j.comgeo.2005.10.005

Liu, G., Xi, Z., and Lien, J. M., 2014. Dual-space decomposition of 2 d complex shapes. In Proceedings of the IEEE Conference on Computer Vision and Pattern Recognition. pp. 4154-4161.

Liu, H., Tolson, B.A., Craig, J.R., Shafii, M. 2016. A priori discretization error metrics for distributed hydrologic modeling applications. Journal of Hydrology. 543, Part B, 873-891. DOI: 10.1016/j.jhydrol.2016.11.008

Moussa, R., 2008. What controls the width function shape, and can it be used for channel network comparison and regionalization? Water Resources Research. 44: W08456. DOI:10.1029/2007WR006118.

Moussa, R., Voltz, M., Andrieux, P., Lagacherie, P., 2000. Hydrological modelling of a farmed Mediterranean catchment. In: Claps, P., Siccardi, F. (Eds.), Proceedings of 
Mediterranean Storms, European Geophysical Society Plinius Conference'99, Maratea, Italy, pp.377-386.

Municipalidad de Lo Barnechea, 2012. Plan Regulador Comunal [Municipal Master Plan] URL: http://www.lobarnechea.cl/newweb/mi_comuna/plan_regulador.php [In Spanish, Accessed 22.02.16]

Nash, J.E. and Sutcliffe, J.V., 1970. River flow forecasting through conceptual models part I-A discussion of principles. Journal of hydrology. 10(3), 282-290. DOI: 10.1016/0022-1694(70)90255-6

O'Callaghan, J.F. and Mark, D.M., 1984. The extraction of drainage networks from digital elevation data. Computer vision, graphics, and image processing. 28(3), 323-344. DOI: $10.1016 / \mathrm{S} 0734-189 \mathrm{X}(84) 80011-0$

Ogden, F.L., Raj Pradhan, N., Downer, C.W., Zahner, J.A., 2011. Relative importance of impervious area, drainage density, width function, and subsurface storm drainage on flood runoff from an urbanized catchment. Water Resources Research, 47, W12503, DOI: 10.1029/2011WR010550.

Neitsch, S.L., Arnold J.G., Kiniry J.R., Williams JR., 2005. Soil and Water Assessment Tool, Theoretical Documentation, Texas Water Resources Institute: College Station, TX.

Paillé, Y., 2010. Conceptualisation et modélisation d'une base de données en vue de son implémentation dans un modèle hydrologique distribué [Conceptualization and modeling of spatial information for distributed hydrological modeling]. Mémoire de Master 2 Cartographie et Gestion des Espaces à Fortes Contraintes, Université de Nantes, 50 pp. [In French].

Passalacqua, P., Do Trung, T., Foufoula-Georgiou, E., Sapiro, G., Dietrich, W.E., 2010. A geometric framework for channel network extraction from lidar: Nonlinear diffusion and geodesic paths. Journal of Geophysical. Research. 115, F01002. DOI:10.1029/2009JF001254.

Pavez, E.F., Lobos, G.A., Jaksic, F.M., 2010. Long-term changes in landscape and in small mammal and raptor assemblages in central Chile. Revista Chilena de Historia Natural. 83(1), 99-111. DOI: 10.4067/S0716-078X2010000100006. 
1010

1011

1012

1013

1014

1015

1016

1017

1018

1019

1020

1021

1022

1023

1024

1025

1026

1027

1028

1029

1030

1031

1032

1033

1034

1035

1036

1037

1038

1039

1040

Puente, C.E. and Sivakumar, B., 2003. A deterministic width function model. Nonlinear Processes in Geophysics. 10 (6), 525-529.

QGIS Development Team, 2015. QGIS Geographic Information System. Open Source Geospatial Foundation Project. Technical report. URL: http://qgis.osgeo.org.

Richards-Pecou, B., 2002. Scale invariance analysis of channel network width function and possible implications for flood behaviour. Hydrological Sciences Journal. 47(3), 387-404. DOI: 10.1080/02626660209492942

Rodriguez, F., Andrieu, H., Morena, F., 2008. A distributed hydrological model for urbanized areas - model development and application to case studies. Journal of Hydrology. 351, 268-287. DOI: 10.1016/j.jhydrol.2007.12.007.

Rodriguez, F., Bocher, E. and Chancibault, K., 2013. Terrain representation impact on periurban catchment morphological properties. Journal of Hydrology. 485, 54-67. DOI: 10.1016/j.jhydrol.2012.11.023

Rodriguez-Iturbe, I., Rinaldo, A., 1997. Fractal River Basins: Chance and Self organization, Ed. Cambridge University Press, New York. 564 pp.

Romero „H., and Vásquez, A., 2005. Evaluación ambiental del proceso de urbanización de las cuencas del piedemonte andino de Santiago de Chile [Environmental Evaluation of the urban growth in the Andean piedmont catchments of Santiago de Chile]. EURE, 31(94), 97-117. DOI:10.4067/S0250-71612005009400006.

Romero H., Ihl M., Rivera A., Zalazar P., Azocar P., 1999. Rapid urban growth, land-use changes and air pollution in Santiago, Chile. Atmospheric Environment. 33 (2425), 4039-4047. DOI: 10.1016/S1352-2310(99)00145-4

Romero, H., Salgado, M., Smith, P., 2010. Cambios climáticos y climas urbanos: Relaciones entre zonas termales y condiciones socioeconómicas de la población de Santiago de Chile [Climate Change and Urban Climate: Relations between thermal zones and the socioeconomic conditions of the population of Santiago de Chile]. Revista INVI. 25(70), 151-179. [In Spanish] DOI:10.4067/S071883582010000300005

Rossel, F., Gironás, J., Mejía, A., Rinaldo, A., Rodriguez, F., 2014. Spatial characterization of catchment dispersion mechanisms in an urban context. Advances in Water Resources. 74, 290-301. DOI: 10.1016/j.advwatres.2014.09.005 
1041

1042

1043

1044

1045

1046

1047

1048

1049

1050

1051

1052

1053

1054

1055

1056

1057

1058

1059

1060

1061

1062

1063

1064

1065

1066

1067

1068

1069

Sangireddy, H., C.P. Stark, A. Kladzyk, P. Passalacqua, 2016. GeoNet: An open source software for the automatic and objective extraction of channel heads, channel network, and channel morphology from high resolution topography data. Environmental Modeling and Software. 83, 58-73, DOI: 10.1016/j.envsoft.2016.04.026.

Santo Domingo, N., Refsgaard, A., Mark, O., Paludan, B., 2010. Flood analysis in mixedurban areas reflecting interactions with the complete water cycle through coupled hydrologic-hydraulic modelling. Water Science and Technology. 62(6), 1386-1392. DOI: 10.2166/wst.2010.365

Sanzana, P., Jankowfsky, S., Branger, F., Braud, I., Vargas, X., Hitschfeld, N., Gironás, J., 2013. Computer-assisted mesh generation based on hydrological response units for distributed hydrological modeling. Computers \& Geosciences. 57, 32-43. DOI: 10.1016/j.cageo.2013.02.006

Sarrazin, B., 2012. Approches spatiales pour décrire le réseau de drainage et suivre sa dynamique de fonctionnement en milieu rural dans une perspective d'aide à la modélisation hydrologique (Spatial approaches to describe the drainage system and follow its dynamics operating in rural areas with a view to support hydrologic modeling). Ph.D. Dissertation, École Doctorale Terre, Univers, Environnement. l'Institut National Polytechnique de Grenoble, [In French].

Schwartze, C., 2008. Deriving Hydrological Response Units (HRUs) using a Web Processing Service implementation based on GRASS-GIS. Geoinformatics FCE CTU 2008. Workshop Proceedings. 3, 67-78.

Seibert, J. and McGlynn, B.L., 2007. A new triangular multiple flow direction algorithm for computing upslope areas from gridded digital elevation models. Water Resources Research. 43(4), WO4501. DOI: 10.1029/2006WR005128

Shewchuck, J., 1996. Triangle: Engineering a 2D Quality Mesh Generator and Delaunay Triangulator, in Lin, M.C., Manocha, D., (Eds.), Applied Computational Geometry: Towards Geometric Engineering. Berlin, Heidelberg. 1148, 203-222. DOI: 10.1007/BFb0014497 
1070

1071

1072

1073

1074

1075

1076

1077

1078

1079

1080

1081

1082

1083

1084

1085

1086

1087

1088

1089

1090

1091

1092

1093

1094

1095

1096

1097

1098

1099

Shuster, W.D., Bonta, J., Thurston, H., Warnemuende, E., Smith, D.R., 2005. Impacts of impervious surface on watershed hydrology: a review. Urban Water Journal. 2(4), 263-275. DOI: 10.1080/15730620500386529

Shynk, J. J., 2012. Probability, Random Variables, and Random Processes: Theory and Signal Processing Applications., first ed. Wiley-Interscience. New-Jersey.

Singh, V. P., 1995. Chapter 1: Watershed Modeling, in Singh, V.P., (Ed.), Computer Models of Watershed Hydrology, Water Resource Publications. 1-22.

SIRA, 2011. Soil Information of Rhône-Alpes. URL: http://www.rhonealpes.chambagri.fr/sira/. [Accessed 31.03.16]

Smith, J.A., Baeck, M.L., Morrison, J.E., Sturdevant-Rees, P., Turner-Gillespie, D.F., Bates, P.D., 2002. The regional hydrology of extreme floods in an urbanizing drainage basin. Journal of Hydrometeorology. 3(3), 267-282. DOI:10.1175/15257541(2002)003<0267:TRHOEF $>2.0 . \mathrm{CO} ; 2$

Smith, J.A., Baeck, M.L., Meierdiercks, K.L., Nelson, P.A., Miller, A.J., Holland, E.J., 2005. Field studies of the storm event hydrologic response in an urbanizing watershed. Water Resources Research. 41, W10413. doi:10.1029/2004WR003712.

Tilmant, F., Gouttevin, I., Barachet, C., Montginoul, M., Branger, F., Leblois, E., Sauquet, E., Braud, I., Noël, D., Le Gros, C., 2015. Modélisation hydrologique distribuée du Rhône [A distributed hydrological model of the Rhône catchment]. Technical Report. [In French], 105 pp.

Toma, L., Wickremesinghe, R., Arge, L., Chase, J.S., Vitter, J.S., Halpin, P.N. and Urban, D., 2001. Flow computation on massive grids. In Proceedings of the 9th ACM international symposium on Advances in geographic information systems, 82-87. DOI: $10.1145 / 512161.512180$

Urban Drainage and Flood Control District (UDFCD), 2001. Urban Storm Drainage Criteria Manual. Revised August 2006, Denver, Colorado. URL:www.udfcd.org/downloads/down_critmanual.ht.

Veneziano, D., Moglen, G.E., Furcolo, P., Iacobellis, V., 2000. Stochastic model of the width function. Water Resources Research. 36(4), 1143-1157. DOI: 10.1029/2000WR900002 
1100 Vietz, G. J., Walsh, C. J., Fletcher, T. D., 2015. Urban hydrogeomorphology and the urban 1101 stream syndrome: Treating the symptoms and causes of geomorphic change.

1104 Viviroli, D., Zappa, M., Gurtz, J., Weingartner, R., 2009. An introduction to the 1105 hydrological modelling system PREVAH and its pre-and post-processing-tools. Environmental Modelling \& Software. 24(10), $1209-1222$.

DOI: 10.1016/j.envsoft.2009.04.001. 